\title{
Dust in brown dwarfs and extra-solar planets
}

\section{Chemical composition and spectral appearance of quasi-static cloud layers}

\author{
Ch. Helling ${ }^{1}$, P. Woitke ${ }^{2}$, and W.-F. Thi ${ }^{3}$ \\ 1 SUPA, School of Physics \& Astronomy, University of St Andrews, North Haugh, St Andrews, KY16 9SS, Scotland, UK \\ e-mail: Christiane.Helling@st-andrews.ac.uk \\ 2 UK Astronomy Technology Centre, Royal Observatory, Blackford Hill, Edinburgh EH9 3HJ, Scotland, UK \\ 3 SUPA, Institute for Astronomy, The University of Edinburgh, Royal Observatory, Blackford Hill, Edinburgh EH9 3HJ, \\ Scotland, UK
}

Received 4 July 2007 / Accepted 21 March 2008

\begin{abstract}
Aims. Brown dwarfs are covered by dust cloud layers which cause inhomogeneous surface features and move below the observable $\tau=1$ level during the object's evolution. The cloud layers have a strong influence on the structure and spectral appearance of brown dwarfs and extra-solar planets, e.g. by providing high local opacities and by removing condensable elements from the atmosphere causing a sub-solar metalicity in the atmosphere. We aim at understanding the formation of cloud layers in quasi-static substellar atmospheres that consist of dirty grains composed of numerous small islands of different solid condensates.

Methods. The time-dependent description is a kinetic model describing nucleation, growth and evaporation. It is extended to treat gravitational settling and is applied to the static-stationary case of substellar model atmospheres. From the solution of the dust moments, we determine the grain size distribution function approximately which, together with the calculated material volume fractions, provides the basis for applying effective medium theory and Mie theory to calculate the opacities of the composite dust grains. Results. The cloud particles in brown dwarfs and hot giant-gas planets are found to be small in the high atmospheric layers $(a \approx 0.01 \mu \mathrm{m})$, and are composed of a rich mixture of all considered condensates, in particular $\mathrm{MgSiO}_{3}[\mathrm{~s}], \mathrm{Mg}_{2} \mathrm{SiO}_{4}[\mathrm{~s}]$ and $\mathrm{SiO}_{2}[\mathrm{~s}]$. As the particles settle downward, they increase in size and reach several $100 \mu \mathrm{m}$ in the deepest layers. The more volatile parts of the grains evaporate and the particles stepwise purify to form composite particles of high-temperature condensates in the deeper layers, mainly made of $\mathrm{Fe}[\mathrm{s}]$ and $\mathrm{Al}_{2} \mathrm{O}_{3}[\mathrm{~s}]$. The gas phase abundances of the elements involved in the dust formation process vary by orders of magnitudes throughout the atmosphere. The grain size distribution is found to be relatively broad in the upper atmospheric layers but strongly peaked in the deeper layers. This reflects the cessation of the nucleation process at intermediate heights. The spectral appearance of the cloud layers in the mid IR $(7-20 \mu \mathrm{m})$ is close to a grey body with only weak broad features of a few percent, mainly caused by $\mathrm{MgSiO}_{3}[\mathrm{~s}]$, and $\mathrm{Mg}_{2} \mathrm{SiO}_{4}[\mathrm{~s}]$. These features are, nevertheless, a fingerprint of the dust in the higher atmospheric layers that can be probed by observations.

Conclusions. Our models predict that the gas phase depletion is much weaker than phase-equilibrium calculations in the high atmospheric layers. Because of the low densities, the dust formation process is incomplete there, which results in considerable amounts of left-over elements that might produce stronger and broader neutral metallic lines.
\end{abstract}

Key words. stars: atmospheres - stars: low mass, brown dwarfs - methods: numerical - astrochemistry

\section{Introduction}

Dust in the form of small solid particles (grains) becomes an increasingly important component in understanding the nature of substellar objects with decreasing $T_{\text {eff }}$, i.e. brown dwarfs and giant-gas planets. Observations have started to provide direct evidence for dust clouds covering brown dwarfs (Cushing et al. 2006) and extrasolar giant-gas planets (Richardson et al. 2007; Swain et al. 2007; Pont et al. 2008; Lecavelier des Etangs et al. 2008). The search for biosignatures in extraterrestrial planets becomes more complicated if such cloud layers cover the atmosphere and efficiently absorb in the wavelength region where e.g. the Earth vegetation's red edge spectroscopic features (600-1100 nm, Seager et al. 2005) or the extraterrestrial equivalents are situated. In fact, the development of life seems impossible below optically thick cloud layers, because the star light needs to reach the surface to create the necessary departures from thermodynamic equilibrium that allow for structure formation. Furthermore, abundances of molecules like $\mathrm{O}_{2}$ and $\mathrm{O}_{3}$ as the carriers of spectral biosignatures will be strongly affected by the presence of cloud layers, because of chemical surface reactions and the element depletion due to dust formation in the atmosphere. Thus, the understanding of the details of cloud formation physics and chemistry is a major issue in modelling substellar atmospheres.

This paper presents a kinetic approach for modelling quasistatic atmospheres with stationary dust cloud layers including seed particle formation (nucleation), grain growth, gravitational settling, grain evaporation, and element conservation (Sects. 2 and 3). The model is a further development of the timedependent description presented in Helling \& Woitke (2006, Paper V) and is particularly suited to treat the formation of "dirty" dust grains (i.e. particles composed of numerous small islands of different solid condensates) in the framework of classical stellar atmospheres with consistent radiative transfer and 
convection (Dehn 2007; Helling et al. 2008). The results of the models (see Sect. 4) describe the vertical cloud structure and the amount of dust formed in the atmosphere of substellar objects as well as the amount of condensable elements left in the gas phase. The models provide further details such as the material composition of the cloud particles, the mean grain sizes and the size distributions as a function of atmospheric height. Section 5 demonstrates what spectral features such cloud layers made of dirty solid particles exhibit, and from which temperature and pressure level these features originate.

\section{Nucleation, growth and evaporation of precipitating dirty grains}

In Paper V, a kinetic description of the nucleation, growth and evaporation of dirty dust particles was developed by extending the time-dependent moment method of Gail \& Sedlmayr (1988). The basic idea is that a "dirty" solid mantle will grow on top of the seed particles, because these seeds can only form at relatively low temperates $(T \lesssim 1400 \mathrm{~K}$ ) where the oxygen-rich gas is strongly supersaturated with respect to several solid materials. The dirty mantle is assumed to be composed of numerous small islands of different pure condensates. The formation of islands is supported by experiments in solid state physics (Ledieu et al. 2005, also Zinke-Allmang 1999) and by observations of coated terrestrial dust particles (Levin et al. 1996; Korhonen et al. 2003). Note that we consider dust formation by gas-solid reactions only and omit solid-solid reactions and lattice rearrangements inside the grains in our model.

In the following, we extend this description to include the effects of gravitational settling (drift, rain-out, precipitation) which is important to understand the long-term quasi-static structures of brown dwarf and gas-giant atmospheres. The challenge here is to properly account for the element conservation when dust particles consume certain elements from the gas phase at the sites of their formation, transport them via drift motions through the gas and finally release the elements by evaporation at other places. Furthermore, we want to abandon the assumption made in Paper $\mathrm{V}$ that the number of elements equals the number of condensates, because there are typically many more condensates than elements.

We consider the moments $L_{j}(\boldsymbol{x}, t)\left[\mathrm{cm}^{j} \mathrm{~g}^{-1}\right](j=0,1,2, \ldots)$ of the dust volume distribution function $f(V, x, t)\left[\mathrm{cm}^{-6}\right]$ (for more details, see Paper V, Sect. 2.1), where $\boldsymbol{x}$ and $t$ are space and time. $V\left[\mathrm{~cm}^{3}\right]$ is the volume of an individual dust particle. The total dust volume per $\mathrm{cm}^{3}$ stellar matter, $V_{\text {tot }}$, is given by the $3 \mathrm{rd}$ dust moment as

$\rho L_{3}=\int_{V_{\ell}}^{\infty} f(V) V \mathrm{~d} V=V_{\text {tot }} \quad\left[\mathrm{cm}^{3} \mathrm{~cm}^{-3}\right]$,

where $\rho\left[\mathrm{g} \mathrm{cm}^{-3}\right]$ is the mass density and $V_{\ell}$ is the lower integration boundary. In an analogous way, we define the volume $V_{\mathrm{s}}$ of a certain solid species $s$ by

$\rho L_{3}^{\mathrm{s}}=\int_{V_{\ell}}^{\infty} f(V) V^{\mathrm{s}} \mathrm{d} V=V_{\mathrm{s}} \quad\left[\mathrm{cm}^{3} \mathrm{~cm}^{-3}\right]$,

where $V^{\mathrm{s}}\left[\mathrm{cm}^{3}\right]$ is the sum of island volumes of material s in one individual dust particle. For simplicity, we assume that $V^{\mathrm{s}} / V=$ $V_{\mathrm{s}} / V_{\text {tot }}$ is constant for all dust particles at a certain position in the atmosphere, i.e. we assume a unique volume composition of all grains at $(\boldsymbol{x}, t)$, such that $V_{\text {tot }}=\sum V_{\mathrm{s}}$ and $L_{3}=\sum L_{3}^{\mathrm{s}}$.

By means of this assumption, it is possible to express the integrals that occur after integrating the master equation (Eq. (1) in Paper V) over size in terms of other moments. The results are the dust moment conservation equations. The change of the partial volume of the solid $s$ can then be expressed analogously to Eq. (23) in Paper V

$$
\begin{array}{r}
\frac{\partial}{\partial t}\left(\rho L_{3}^{\mathrm{s}}\right)+\nabla\left(\int_{V_{\ell}}^{\infty} f(V) V^{\mathrm{s}}\right. \\
\left.\left(\boldsymbol{v}_{\text {gas }}+\stackrel{\circ}{\mathbf{d} r}(V)\right) \mathrm{d} V\right) \\
=V_{\ell}^{\mathrm{s}} J_{\star}+\chi_{\text {net }}^{\mathrm{s}} \rho L_{2}
\end{array}
$$

where we have assumed that the Knudsen numbers are large $\left(\mathrm{Kn} \gg 1\right.$, compare Paper II) and that the drift velocities $\boldsymbol{v}_{\mathrm{dr}}(V)$ of the dust particles can be approximated by the equilibrium drift velocities $\boldsymbol{v}_{\mathrm{dr}}(V)$ (final fall speeds).

The source terms on the rhs of Eq. (3) describe the effects of nucleation, growth and evaporation of condensate $s$. $J_{\star}=J\left(V_{\ell}\right)=\left.f\left(V_{\ell}\right) \frac{\mathrm{d} V}{\mathrm{~d} t}\right|_{V=V_{l}}\left[\mathrm{~s}^{-1} \mathrm{~cm}^{-3}\right]$ is the stationary nucleation rate (see Sect. 3.3). $V_{\ell}^{\mathrm{s}}\left[\mathrm{cm}^{3}\right]$ is the volume occupied by condensate $s$ in the seed particles when they enter the integration domain in size space. The net growth velocity of condensate $\mathrm{s}$ $\chi_{\text {net }}^{\mathrm{s}}\left[\mathrm{cm} \mathrm{s}^{-1}\right]$ (negative for evaporation) is given by (Eq. (24) in Paper V)

$\chi_{\text {net }}^{\mathrm{s}}=\sqrt[3]{36 \pi} \sum_{r=1}^{R} \frac{\Delta V_{r}^{\mathrm{s}} n_{r}^{\mathrm{key}} v_{r}^{\mathrm{rel}} \alpha_{r}}{v_{r}^{\mathrm{key}}}\left(1-\frac{1}{S_{r} b_{\text {surf }}^{\mathrm{s}}}\right)$.

Here, $r$ is an index for the chemical surface reactions (see Table 1), $\Delta V_{r}^{\mathrm{s}}$ is the volume increment of solid s by reaction $r\left(\sum \Delta V_{r}^{\mathrm{s}}=\Delta V_{\mathrm{r}}\right), n_{r}^{\mathrm{key}}$ is the particle density of the key reactant, $v_{r}^{\text {rel }}$ is its thermal relative velocity and $\alpha_{r}$ is the sticking coefficient of reaction $r . S_{r}$ is the reaction supersaturation ratio and $b_{\text {surf }}^{\mathrm{s}}=V_{\text {tot }} / V_{\mathrm{s}}$ is a $b$-factor which describes the probability of finding a surface of kind $s$ on the total surface. Putting $b_{\text {surf }}^{\mathrm{s}}$ independent of $V$, we assume that all grains at a certain point in the atmosphere have the same surface and volume composition, i.e. the grain material is a homogeneous mix of islands of different kinds (for more details see Paper V).

The divergence of the drift term in Eq. (3) is treated in the following way. Assuming large Knudsen numbers and subsonic drift velocities, the equilibrium drift velocity is given by $\stackrel{0}{\mathrm{dr}}_{\mathrm{dr}}(V)=-\boldsymbol{e}_{z} a \sqrt{\pi} g \rho_{\mathrm{d}} /\left(2 \rho c_{\mathrm{T}}\right)$ (Eq. (63) in Paper II), where $a$ is the particle radius, $\boldsymbol{e}_{z}$ the vertical unit vector (pointing upwards) and $g$ the gravitational acceleration (downwards). $\rho_{\mathrm{d}}=$ $\sum \rho_{\mathrm{s}} V_{\mathrm{s}} / V_{\text {tot }}$ is the dirty dust material density and $\rho_{\mathrm{s}}$ the material density of a pure condensate s. $c_{T}=\sqrt{2 k T / \bar{\mu}}$ is the mean thermal velocity with $T$ being the temperature, $k$ the Boltzmann constant and $\bar{\mu}$ the mean molecular weight of the gas particles. Inserting this formula into the drift term in Eq. (3) yields

$$
\int_{V_{\ell}}^{\infty} f(V) V^{\mathrm{s}} \boldsymbol{v}_{\mathrm{dr}}(V) \mathrm{d} V=-\boldsymbol{e}_{z} \xi_{\mathrm{IKn}} \frac{\rho_{\mathrm{d}}}{c_{T}} \frac{V_{\mathrm{s}}}{V_{\mathrm{tot}}} L_{4}
$$

with the abbreviation $\xi_{1 \mathrm{Kn}}=\left(\frac{3}{4 \pi}\right)^{1 / 3} \frac{\sqrt{\pi}}{2} g$ (note the difference to Eq. (3) in Paper III). Defining $L_{4}^{\mathrm{s}}=L_{4} V_{\mathrm{s}} / V_{\text {tot }}$, Eq. (3) in this paper can be rewritten as

$$
\frac{\partial}{\partial t}\left(\rho L_{3}^{\mathrm{s}}\right)+\nabla\left(\rho L_{3}^{\mathrm{s}} \boldsymbol{v}_{\mathrm{gas}}\right)=V_{\ell}^{\mathrm{s}} J_{\star}+\chi_{\mathrm{net}}^{\mathrm{s}} \rho L_{2}+\xi_{\mathrm{IKn}} \frac{\partial}{\partial z}\left(\frac{\rho_{\mathrm{d}}}{c_{T}} L_{4}^{\mathrm{s}}\right) .
$$

Equation (6) describes the evolution of the partial dust volume of solid s in space and time due to advection, nucleation, growth, evaporation and drift. 
Table 1. Chemical surface reactions $r$ assumed to form the solid materials s. The efficiency of the reaction is limited by the collision rate of the key species, which has the lowest abundance among the reactants. The notation $1 \frac{1}{2}$ in the rhs column means that only every second collision (and sticking) event initiates one reaction (see $v_{r}^{\mathrm{key}}$ in Eqs. (4) and (10)). Data sources for the supersaturation ratios (and saturation vapour pressures): (1) Helling \& Woitke (2006); (2) Nuth \& Ferguson (2006); (3) Sharp \& Huebner (1990).

\begin{tabular}{|c|c|c|c|}
\hline Index $r$ & Solid s & Surface reaction & Key species \\
\hline 1 & $\mathrm{TiO}_{2}[\mathrm{~s}]$ & $\mathrm{TiO}_{2} \longrightarrow \mathrm{TiO}_{2}[\mathrm{~s}]$ & $\mathrm{TiO}_{2}$ \\
\hline 2 & rutile & $\mathrm{Ti}+2 \mathrm{H}_{2} \mathrm{O} \longrightarrow \mathrm{TiO}_{2}[\mathrm{~s}]+2 \mathrm{H}_{2}$ & $\mathrm{Ti}$ \\
\hline 3 & $(1)$ & $\mathrm{TiO}+\mathrm{H}_{2} \mathrm{O} \longrightarrow \mathrm{TiO}_{2}[\mathrm{~s}]+\mathrm{H}_{2}$ & $\mathrm{TiO}$ \\
\hline 4 & & $\mathrm{TiS}+2 \mathrm{H}_{2} \mathrm{O} \longrightarrow \mathrm{TiO}_{2}[\mathrm{~s}]+\mathrm{H}_{2} \mathrm{~S}+\mathrm{H}_{2}$ & TiS \\
\hline 5 & $\mathrm{SiO}_{2}[\mathrm{~s}]$ & $\mathrm{SiO}_{2} \longrightarrow \mathrm{SiO}_{2}[\mathrm{~s}]$ & $\mathrm{SiO}_{2}$ \\
\hline 6 & silica & $\mathrm{SiO}+\mathrm{H}_{2} \mathrm{O} \longrightarrow \mathrm{SiO}_{2}[\mathrm{~s}]+\mathrm{H}_{2}$ & $\mathrm{SiO}$ \\
\hline 7 & (3) & $\mathrm{SiS}+2 \mathrm{H}_{2} \mathrm{O} \longrightarrow \mathrm{SiO}_{2}[\mathrm{~s}]+\mathrm{H}_{2} \mathrm{~S}+\mathrm{H}_{2}$ & $\mathrm{SiS}$ \\
\hline 8 & $\mathrm{SiO}[\mathrm{s}]$ & $\mathrm{SiO} \longrightarrow \mathrm{SiO}[\mathrm{s}]$ & $\mathrm{SiO}$ \\
\hline 9 & silicon mono-oxide & $\mathrm{SiO}_{2}+\mathrm{H}_{2} \longrightarrow \mathrm{SiO}[\mathrm{s}]+\mathrm{H}_{2} \mathrm{O}$ & $\mathrm{SiO}_{2}$ \\
\hline 10 & (2) & $\mathrm{SiS}+\mathrm{H}_{2} \mathrm{O} \longrightarrow \mathrm{SiO}[\mathrm{s}]+\mathrm{H}_{2} \mathrm{~S}$ & $\mathrm{SiS}$ \\
\hline 11 & $\mathrm{Fe}[\mathrm{s}]$ & $\mathrm{Fe} \longrightarrow \mathrm{Fe}[\mathrm{s}]$ & $\mathrm{Fe}$ \\
\hline 12 & solid iron & $\mathrm{FeO}+\mathrm{H}_{2} \longrightarrow \mathrm{Fe}[\mathrm{s}]+\mathrm{H}_{2} \mathrm{O}$ & $\mathrm{FeO}$ \\
\hline 13 & (1) & $\mathrm{FeS}+\mathrm{H}_{2} \longrightarrow \mathrm{Fe}[\mathrm{s}]+\mathrm{H}_{2} \mathrm{~S}$ & $\mathrm{FeS}$ \\
\hline 14 & & $\mathrm{Fe}(\mathrm{OH})_{2}+\mathrm{H}_{2} \longrightarrow \mathrm{Fe}[\mathrm{s}]+2 \mathrm{H}_{2} \mathrm{O}$ & $\mathrm{Fe}(\mathrm{OH})_{2}$ \\
\hline 15 & $\mathrm{FeO}[\mathrm{s}]$ & $\mathrm{FeO} \longrightarrow \mathrm{FeO}[\mathrm{s}]$ & $\mathrm{FeO}$ \\
\hline 16 & iron (II) oxide & $\mathrm{Fe}+\mathrm{H}_{2} \mathrm{O} \longrightarrow \mathrm{FeO}[\mathrm{s}]+\mathrm{H}_{2}$ & $\mathrm{Fe}$ \\
\hline 17 & (3) & $\mathrm{FeS}+\mathrm{H}_{2} \mathrm{O} \longrightarrow \mathrm{FeO}[\mathrm{s}]+\mathrm{H}_{2} \mathrm{~S}$ & $\mathrm{FeS}$ \\
\hline 18 & & $\mathrm{Fe}(\mathrm{OH})_{2} \longrightarrow \mathrm{FeO}[\mathrm{s}]+\mathrm{H}_{2}$ & $\mathrm{Fe}(\mathrm{OH})_{2}$ \\
\hline 19 & $\mathrm{FeS}[\mathrm{s}]$ & $\mathrm{FeS} \longrightarrow \mathrm{FeS}[\mathrm{s}]$ & $\mathrm{FeS}$ \\
\hline 20 & iron sulphide & $\mathrm{Fe}+\mathrm{H}_{2} \mathrm{~S} \longrightarrow \mathrm{FeS}[\mathrm{s}]+\mathrm{H}_{2}$ & $\mathrm{Fe}$ \\
\hline 21 & (3) & $\mathrm{FeO}+\mathrm{H}_{2} \mathrm{~S} \longrightarrow \mathrm{FeS}[\mathrm{s}]+\mathrm{H}_{2} \mathrm{O}$ & $\min \left\{\mathrm{FeO}, \mathrm{H}_{2} \mathrm{~S}\right\}$ \\
\hline 22 & & $\mathrm{Fe}(\mathrm{OH})_{2}+\mathrm{H}_{2} \mathrm{~S} \longrightarrow \mathrm{FeS}[\mathrm{s}]+2 \mathrm{H}_{2} \mathrm{O}$ & $\min \left\{\mathrm{Fe}(\mathrm{OH})_{2}, \mathrm{H}_{2} \mathrm{~S}\right\}$ \\
\hline 23 & $\mathrm{Fe}_{2} \mathrm{O}_{3}[\mathrm{~s}]$ & $2 \mathrm{Fe}+3 \mathrm{H}_{2} \mathrm{O} \longrightarrow \mathrm{Fe}_{2} \mathrm{O}_{3}[\mathrm{~s}]+3 \mathrm{H}_{2}$ & $1 / 2 \mathrm{Fe}$ \\
\hline 24 & iron (III) oxide & $2 \mathrm{FeO}+\mathrm{H}_{2} \mathrm{O} \longrightarrow \mathrm{Fe}_{2} \mathrm{O}_{3}[\mathrm{~s}]+\mathrm{H}_{2}$ & $1 / 2 \mathrm{FeO}$ \\
\hline 25 & (3) & $2 \mathrm{FeS}+3 \mathrm{H}_{2} \mathrm{O} \longrightarrow \mathrm{Fe}_{2} \mathrm{O}_{3}[\mathrm{~s}]+2 \mathrm{H}_{2} \mathrm{~S}+\mathrm{H}_{2}$ & $1 / 2 \mathrm{FeS}$ \\
\hline 26 & & $2 \mathrm{Fe}(\mathrm{OH})_{2} \longrightarrow \mathrm{Fe}_{2} \mathrm{O}_{3}[\mathrm{~s}]+\mathrm{H}_{2} \mathrm{O}+\mathrm{H}_{2}$ & $1 / 2 \mathrm{Fe}(\mathrm{OH})_{2}$ \\
\hline 27 & $\mathrm{MgO}[\mathrm{s}]$ & $\mathrm{MgO} \longrightarrow \mathrm{MgO}[\mathrm{s}]$ & $\mathrm{MgO}$ \\
\hline 28 & periclase & $\mathrm{Mg}+\mathrm{H}_{2} \mathrm{O} \longrightarrow \mathrm{MgO}[\mathrm{s}]+\mathrm{H}_{2}$ & $\mathrm{Mg}$ \\
\hline 29 & (3) & $2 \mathrm{MgOH} \longrightarrow 2 \mathrm{MgO}[\mathrm{s}]+\mathrm{H}_{2}$ & $1 / 2 \mathrm{MgOH}$ \\
\hline 30 & & $\mathrm{Mg}(\mathrm{OH})_{2} \longrightarrow \mathrm{MgO}[\mathrm{s}]+\mathrm{H}_{2} \mathrm{O}$ & $\mathrm{Mg}(\mathrm{OH})_{2}$ \\
\hline 31 & $\mathrm{MgSiO}_{3}[\mathrm{~s}]$ & $\mathrm{Mg}+\mathrm{SiO}+2 \mathrm{H}_{2} \mathrm{O} \longrightarrow \mathrm{MgSiO}_{3}[\mathrm{~s}]+\mathrm{H}_{2}$ & $\min \{\mathrm{Mg}, \mathrm{SiO}\}$ \\
\hline 32 & enstatite & $\mathrm{Mg}+\mathrm{SiS}+3 \mathrm{H}_{2} \mathrm{O} \longrightarrow \mathrm{MgSiO}_{3}[\mathrm{~s}]+\mathrm{H}_{2} \mathrm{~S}+2 \mathrm{H}_{2}$ & $\min \{\mathrm{Mg}, \mathrm{SiS}\}$ \\
\hline 33 & (3) & $2 \mathrm{MgOH}+2 \mathrm{SiO}+2 \mathrm{H}_{2} \mathrm{O} \longrightarrow 2 \mathrm{MgSiO}_{3}[\mathrm{~s}]+3 \mathrm{H}_{2}$ & $\min \{1 / 2 \mathrm{MgOH}, 1 / 2 \mathrm{SiO}\}$ \\
\hline 34 & & $2 \mathrm{MgOH}+2 \mathrm{SiS}+2 \mathrm{H}_{2} \mathrm{O} \longrightarrow 2 \mathrm{MgSiO}_{3}[\mathrm{~s}]+2 \mathrm{H}_{2} \mathrm{~S}+2 \mathrm{H}_{2}$ & $\min \{1 / 2 \mathrm{MgOH}, 1 / 2 \mathrm{SiS}\}$ \\
\hline 35 & & $\mathrm{Mg}(\mathrm{OH})_{2}+\mathrm{SiO} \longrightarrow 2 \mathrm{MgSiO}_{3}[\mathrm{~s}]+\mathrm{H}_{2}$ & $\min \left\{\mathrm{Mg}(\mathrm{OH})_{2}, \mathrm{SiO}\right\}$ \\
\hline 36 & & $\mathrm{Mg}(\mathrm{OH})_{2}+\mathrm{SiS}+\mathrm{H}_{2} \mathrm{O} \longrightarrow \mathrm{MgSiO}_{3}[\mathrm{~s}]+\mathrm{H}_{2} \mathrm{~S}+\mathrm{H}_{2}$ & $\min \left\{\mathrm{Mg}(\mathrm{OH})_{2}, \mathrm{SiS}\right\}$ \\
\hline 37 & $\mathrm{Mg}_{2} \mathrm{SiO}_{4}[\mathrm{~s}]$ & $2 \mathrm{Mg}+\mathrm{SiO}+3 \mathrm{H}_{2} \mathrm{O} \longrightarrow \mathrm{Mg}_{2} \mathrm{SiO}_{4}[\mathrm{~s}]+3 \mathrm{H}_{2}$ & $\min \{1 / 2 \mathrm{Mg}, \mathrm{SiO}\}$ \\
\hline 38 & forsterite & $2 \mathrm{MgOH}+\mathrm{SiO}+\mathrm{H}_{2} \mathrm{O} \longrightarrow \mathrm{Mg}_{2} \mathrm{SiO}_{4}[\mathrm{~s}]+2 \mathrm{H}_{2}$ & $\min \left\{1 \frac{1}{2} \mathrm{MgOH}, \mathrm{SiO}\right\}$ \\
\hline 39 & (3) & $2 \mathrm{Mg}(\mathrm{OH})_{2}+\mathrm{SiO} \longrightarrow \mathrm{Mg}_{2} \mathrm{SiO}_{4}[\mathrm{~s}]+\mathrm{H}_{2} \mathrm{O}+\mathrm{H}_{2}$ & $\min \left\{1 / 2 \mathrm{Mg}(\mathrm{OH})_{2}, \mathrm{SiO}\right\}$ \\
\hline 40 & & $2 \mathrm{Mg}+\mathrm{SiS}+4 \mathrm{H}_{2} \mathrm{O} \longrightarrow \mathrm{Mg}_{2} \mathrm{SiO}_{4}[\mathrm{~s}]+\mathrm{H}_{2} \mathrm{~S}+3 \mathrm{H}_{2}$ & $\min \{1 / 2 \mathrm{Mg}, \mathrm{SiS}\}$ \\
\hline 41 & & $2 \mathrm{MgOH}+\mathrm{SiS}+2 \mathrm{H}_{2} \mathrm{O} \longrightarrow \mathrm{Mg}_{2} \mathrm{SiO}_{4}[\mathrm{~s}]+\mathrm{H}_{2} \mathrm{~S}+2 \mathrm{H}_{2}$ & $\min \left\{1 \frac{1}{2} \mathrm{MgOH}, \mathrm{SiS}\right\}$ \\
\hline 42 & & $2 \mathrm{Mg}(\mathrm{OH})_{2}+\mathrm{SiS} \longrightarrow \mathrm{Mg}_{2} \mathrm{SiO}_{4}[\mathrm{~s}]+\mathrm{H}_{2}+\mathrm{H}_{2} \mathrm{~S}$ & $\min \left\{1 / 2 \mathrm{Mg}(\mathrm{OH})_{2}, \mathrm{SiS}\right\}$ \\
\hline 43 & $\mathrm{Al}_{2} \mathrm{O}_{3}[\mathrm{~s}]$ & $2 \mathrm{Al}+3 \mathrm{H}_{2} \mathrm{O} \longrightarrow \mathrm{Al}_{2} \mathrm{O}_{3}[\mathrm{~s}]+3 \mathrm{H}_{2}$ & $1 / 2 \mathrm{Al}$ \\
\hline 44 & aluminia & $2 \mathrm{AlOH}+\mathrm{H}_{2} \mathrm{O} \longrightarrow \mathrm{Al}_{2} \mathrm{O}_{3}[\mathrm{~s}]+2 \mathrm{H}_{2}$ & $1 / 2 \mathrm{AlOH}$ \\
\hline 45 & (3) & $2 \mathrm{AlH}+3 \mathrm{H}_{2} \mathrm{O} \longrightarrow \mathrm{Al}_{2} \mathrm{O}_{3}[\mathrm{~s}]+4 \mathrm{H}_{2}$ & $1 / 2 \mathrm{AlH}$ \\
\hline 46 & & $\mathrm{Al}_{2} \mathrm{O}+2 \mathrm{H}_{2} \mathrm{O} \longrightarrow \mathrm{Al}_{2} \mathrm{O}_{3}[\mathrm{~s}]+2 \mathrm{H}_{2}$ & $\mathrm{Al}_{2} \mathrm{O}$ \\
\hline 47 & & $2 \mathrm{AlS}+3 \mathrm{H}_{2} \mathrm{O} \longrightarrow \mathrm{Al}_{2} \mathrm{O}_{3}[\mathrm{~s}]+2 \mathrm{H}_{2} \mathrm{~S}+\mathrm{H}_{2}$ & $1 / 2 \mathrm{AlS}$ \\
\hline 48 & & $2 \mathrm{AlO}_{2} \mathrm{H} \longrightarrow \mathrm{Al}_{2} \mathrm{O}_{3}[\mathrm{~s}]+\mathrm{H}_{2} \mathrm{O}$ & $1 / 2 \mathrm{AlO}_{2} \mathrm{H}$ \\
\hline 49 & $\mathrm{CaTiO}_{3}[\mathrm{~s}]$ & $\mathrm{Ca}+\mathrm{TiO}+2 \mathrm{H}_{2} \mathrm{O} \longrightarrow \mathrm{CaTiO}_{3}[\mathrm{~s}]+2 \mathrm{H}_{2}$ & $\min \{\mathrm{Ca}, \mathrm{TiO}\}$ \\
\hline 50 & perovskite & $\mathrm{Ca}+\mathrm{TiO}_{2}+\mathrm{H}_{2} \mathrm{O} \longrightarrow \mathrm{CaTiO}_{3}[\mathrm{~s}]+\mathrm{H}_{2}$ & $\min \left\{\mathrm{Ca}, \mathrm{TiO}_{2}\right\}$ \\
\hline 51 & (3) & $\mathrm{Ca}+\mathrm{Ti}+3 \mathrm{H}_{2} \mathrm{O} \longrightarrow \mathrm{CaTiO}_{3}[\mathrm{~s}]+3 \mathrm{H}_{2}$ & $\min \{\mathrm{Ca}, \mathrm{Ti}\}$ \\
\hline 52 & & $\mathrm{CaO}+\mathrm{Ti}+2 \mathrm{H}_{2} \mathrm{O} \longrightarrow \mathrm{CaTiO}_{3}[\mathrm{~s}]+2 \mathrm{H}_{2}$ & $\min \{\mathrm{CaO}, \mathrm{Ti}\}$ \\
\hline 53 & & $\mathrm{CaO}+\mathrm{TiO}+\mathrm{H}_{2} \mathrm{O} \longrightarrow \mathrm{CaTiO}_{3}[\mathrm{~s}]+\mathrm{H}_{2}$ & $\min \{\mathrm{CaO}, \mathrm{TiO}\}$ \\
\hline 54 & & $\mathrm{CaO}+\mathrm{TiO}_{2} \longrightarrow \mathrm{CaTiO}_{3}[\mathrm{~s}]$ & $\min \left\{\mathrm{CaO}, \mathrm{TiO}_{2}\right\}$ \\
\hline 55 & & $\mathrm{CaS}+\mathrm{Ti}+3 \mathrm{H}_{2} \mathrm{O} \longrightarrow \mathrm{CaTiO}_{3}[\mathrm{~s}]+\mathrm{H}_{2} \mathrm{~S}+\mathrm{H}_{2}$ & $\min \{\mathrm{CaS}, \mathrm{Ti}\}$ \\
\hline 56 & & $\mathrm{CaS}+\mathrm{TiO}+2 \mathrm{H}_{2} \mathrm{O} \longrightarrow \mathrm{CaTiO}_{3}[\mathrm{~s}]+\mathrm{H}_{2} \mathrm{~S}+2 \mathrm{H}_{2}$ & $\min \{\mathrm{CaS}, \mathrm{TiO}\}$ \\
\hline 57 & & $\mathrm{CaS}+\mathrm{TiO}_{2}+\mathrm{H}_{2} \mathrm{O} \longrightarrow \mathrm{CaTiO}_{3}[\mathrm{~s}]+\mathrm{H}_{2} \mathrm{~S}$ & $\min \left\{\mathrm{CaS}, \mathrm{TiO}_{2}\right\}$ \\
\hline 58 & & $\mathrm{Ca}(\mathrm{OH})_{2}+\mathrm{Ti}+\mathrm{H}_{2} \mathrm{O} \longrightarrow \mathrm{CaTiO}_{3}[\mathrm{~s}]+2 \mathrm{H}_{2}$ & $\min \left\{\mathrm{Ca}(\mathrm{OH})_{2}, \mathrm{Ti}\right\}$ \\
\hline 59 & & $\mathrm{Ca}(\mathrm{OH})_{2}+\mathrm{TiO} \longrightarrow \mathrm{CaTiO}_{3}[\mathrm{~s}]+\mathrm{H}_{2}$ & $\min \left\{\mathrm{Ca}(\mathrm{OH})_{2}, \mathrm{TiO}\right\}$ \\
\hline 60 & & $\mathrm{Ca}(\mathrm{OH})_{2}+\mathrm{TiO}_{2} \longrightarrow \mathrm{CaTiO}_{3}[\mathrm{~s}]+\mathrm{H}_{2} \mathrm{O}$ & $\min \left\{\mathrm{Ca}(\mathrm{OH})_{2}, \mathrm{TiO}_{2}\right\}$ \\
\hline
\end{tabular}

The third moment equation for the total dust volume $\rho L_{3}$ (Eq. (1) in Paper III) can be retrieved by summing the contributions from all condensates $s$ as given by Eq. (6), because

$$
\sum_{\mathrm{s}} L_{3}^{\mathrm{s}}=L_{3}, \sum_{\mathrm{s}} L_{4}^{\mathrm{s}}=L_{4}, \sum_{\mathrm{s}} \chi_{\mathrm{net}}^{\mathrm{s}}=\chi^{\mathrm{net}}, \sum_{\mathrm{s}} V_{\ell}^{\mathrm{s}}=V_{\ell} .
$$

\subsection{Quasi-static, stationary case}

In the case of a plane-parallel quasi-static stellar atmosphere $\boldsymbol{v}_{\text {gas }}=0$ and the dust component is stationary $\frac{\partial}{\partial t}\left(\rho L_{j}\right)=0$, i.e. the lhs of the moment equations vanish. Introducing a convective 
mixing on time scale $\tau_{\text {mix }}{ }^{1}$, we have derived the following equations in Paper III for this case (see Eq. (7) in Paper III)

$$
-\frac{\mathrm{d}}{\mathrm{d} z}\left(\frac{\rho_{\mathrm{d}}}{c_{\mathrm{T}}} L_{j+1}\right)=\frac{1}{\xi_{1 \mathrm{Kn}}}\left(-\frac{\rho L_{j}}{\tau_{\mathrm{mix}}}+V_{\ell}^{j / 3} J_{\star}+\frac{j}{3} \chi^{\mathrm{net}} \rho L_{\mathrm{j}-1}\right) .
$$

These are the moment equations with respect to the total dust volume for dirty grains and we use them for $j=0,1,2$. As outlined in (Eq. (9) in Paper III), $\tau_{\text {mix }}$ is the timescale for mixing due to convective motion and overshoot which decreases rapidly above the convective layers with increasing height in the atmosphere. However, instead of using Eq. (8) with $j=3$ for one pure condensate, we have to use a set of equations for dirty grains, i.e. the third dust moment equations for all volume contributions, that is, one equation for each condensate $s$ taken into account. From (Eq. (6)) we find

$$
-\frac{\mathrm{d}}{\mathrm{d} z}\left(\frac{\rho_{\mathrm{d}}}{c_{\mathrm{T}}} L_{4}^{\mathrm{s}}\right)=\frac{1}{\xi_{1 \mathrm{Kn}}}\left(-\frac{\rho L_{3}^{\mathrm{s}}}{\tau_{\text {mix }}}+V_{\ell}^{\mathrm{s}} J_{\star}+\chi_{\text {net }}^{\mathrm{s}} \rho L_{2}\right) .
$$

Equations (8) for $j \in\{0,1,2\}$ and Eqs. (9) for $\mathrm{s} \in\{1,2, \ldots, S\}$ ( $S$ is the number of solid condensates taken into account) form a system of $(S+3)$ ordinary differential equations for the unknowns $\left\{L_{1}, L_{2}, L_{3}, L_{4}^{\mathrm{s}}\right\}$.

The element conservation equations are not affected by the drift motion of the dust grains. Therefore, Eq. (29) in Paper V remains valid, from which we derived in the static stationary case (compare Eq. (8) in Paper III)

$$
\begin{aligned}
\frac{n_{\langle\mathrm{H}\rangle}\left(\epsilon_{i}^{0}-\epsilon_{i}\right)}{\tau_{\text {mix }}}= & v_{i, 0} N_{\ell} J_{\star}+\sqrt[3]{36 \pi} \rho L_{2} \\
& \times \sum_{r=1}^{R} \frac{v_{i, s} n_{r}^{\mathrm{key}} v_{r}^{\mathrm{rel}} \alpha_{r}}{v_{r}^{\mathrm{key}}}\left(1-\frac{1}{S_{r} b_{\text {surf }}^{\mathrm{s}}}\right),
\end{aligned}
$$

where $i$ enumerates the elements. $N_{\ell}$ is the number of monomers in the seed particles when they enter the size integration domain and $v_{i, 0}$ is the stoichiometric coefficient of the seeds $\left(\mathrm{TiO}_{2}\right.$ seeds: 1 for $i=\mathrm{Ti}$ and 2 for $i=\mathrm{O}$ ). $v_{i, \mathrm{~s}}$ is the stoichiometric coefficient of element $i$ in solid material s.

The element conservation equations (Eq. (10)) provide algebraic auxiliary conditions for the ODE system (Eqs. (8) and (9)) in the static stationary case, i.e. one first has to solve the system of non-linear algebraic Eqs. (10) for $\epsilon_{i}$ at given $\left\{L_{2}, L_{4}^{\mathrm{s}}\right\}$ (the dust volume composition $b_{\text {surf }}^{\mathrm{s}}$ is known from $L_{4}^{\mathrm{s}}$ ) before the rhs of the ODE-equations can be calculated. Since $J_{\star}, n_{r}^{\mathrm{key}}$ and in particular $S_{r}$, however, depend strongly on $\epsilon_{i}$, this requires a complicated iterative procedure which creates the most problems in practise.

\subsection{Grain size distribution function}

The dust opacity calculations with effective medium theory and Mie theory (see Sect. 5) require the dust particle size distribution

\footnotetext{
${ }^{1}$ Our mixing approach is very much simplified, assuming that the gas/dust mix at height $z$ is exchanged by dust-free gas from the deep interior of the object with element abundances $\epsilon_{j}^{0}$ on a mixing timescale $\tau_{\text {mix }}(z)$ which is adapted to the results of $3 \mathrm{D}$ hydrodynamical models (Ludwig et al. 2003, 2006). Other works consider a diffusive mixing here (Ackerman \& Marley 2001 in Cushing et al. 2007; Rossow 1978 in Warren et al. 2007). Interestingly, our model approach and the approach by Ackerman \& Marley (2001) yield comparably results regarding the location of the cloud layer and the maximum dust-to-gas-ratio as can be seen from a comparative study of dust cloud models (Helling et al. 2008b).
}

function $f(a)\left[\mathrm{cm}^{-4}\right]$ at every depth in the atmosphere, where $a[\mathrm{~cm}]$ is the particle radius. This function is not a direct result of the dust moment method applied in this paper. Only the total dust particle number density $n_{\mathrm{d}}=\rho L_{0}$ and the mean particle size $\langle a\rangle=\sqrt[3]{3 /(4 \pi)} L_{1} / L_{0}$ are direct results that have been used in Helling et al. (2006). In this paper, we reconstruct $f(a)$ from the calculated dust moments $L_{j}(j=1 \ldots 4)$ in an approximate way. We want to avoid the zeroth moment, because it is only determined by a closure condition. The idea is to introduce a suitable functional formula for $f(a)$ with a set of four free coefficients, and then determine these coefficients from the known dust moments. For further details, see Appendix A. Two possible functions for $f(a)$ are discussed in Appendices A.1 and A.2.

\subsection{Closure condition}

Since $L_{0}$ appears only on the rhs of Eq. (8) for $j=0$, we need a closure condition in the form $L_{0}=L_{0}\left(L_{1}, L_{2}, L_{3}, L_{4}\right)$ to solve our ODE-system. In this paper, we use the results of the size distribution reconstruction technique explained in Appendix A in application to the double delta-peaked size distribution function and write the zeroth dust moment as

$\rho L_{0}=N_{1}+N_{2}$,

where the two dust particle densities $N_{1}$ and $N_{2}\left[\mathrm{~cm}^{-3}\right]$ are introduced in Appendix A.1.

\section{Material equations and input data}

To solve our model equations, we need an atmospheric $\left(T, p, v_{\text {conv }}\right)$-structure and additional material equations to calculate the number densities of the key reactants $n_{r}^{\text {key }}$, the nucleation rate $J_{\star}$, the reaction supersaturation ratios $S_{r}$, and the sticking probabilities $\alpha_{r}$.

\subsection{Atmospheric (T,p)-structure}

The approach of this paper is to investigate the behaviour of the dust component in quasi-static substellar atmospheres and to propose how our approach to treat the micro-physical processes of the formation of composite dust grains (see Sect. 2) can be included in the framework of stellar atmosphere codes.

For this purpose, it is sufficient to use a given $\left(T, p, v_{\text {conv }}\right)$ structure representing a brown dwarf or giant-gas atmosphere. The atmospheric structure used for our models are cond AMES atmosphere structures $^{2}$. The feedback of the dust formation and the presence of the dust on the atmospheric structure is thereby neglected in this paper, although the model code to calculate the $\left(T, p, v_{\text {conv }}\right)$ structures did incorporate some dust modelling (Allard et al. 2001). Such a decoupled approach may not be entirely satisfying, but the understanding of the physics of cloud layers requires some basic studies, before the feedback mechanisms can be attacked in the frame of highly nonlinear stellar atmosphere codes. For consistent models of our dust treatment in the PHOENIX stellar atmosphere code including radiative transfer and convection see (Dehn 2007; Helling et al. 2008a).

\subsection{Gas-phase chemistry}

We calculate the particle densities of all gaseous species, including $n_{r}^{\text {key }}$ as described in Paper III according to pressure, temperature and the calculated, depth-dependent element abundances $\epsilon_{i}$

\footnotetext{
2 ftp.ens-lyon.fr/pub/users/CRAL/fallard/
} 
in chemical equilibrium. For the well-mixed, deep element abundances $\epsilon_{i}^{0}$ we use solar abundances according to the cond AMES input model. For those elements that are not included in the calculations (abundances are calculated for $\mathrm{Mg}, \mathrm{Si}, \mathrm{Ti}, \mathrm{O}, \mathrm{Fe}, \mathrm{Al}$, $\mathrm{Ca}, \mathrm{S})$, we put $\epsilon_{i}=\epsilon_{i}^{0}$.

\subsection{Nucleation}

The nucleation rate $J_{\star}$ is calculated for $\left(\mathrm{TiO}_{2}\right)_{N}$-clusters according to Eq. (34) in Paper V, applying the modified classical nucleation theory of Gail et al. (1984). We use the value of the surface tension $\sigma$ fitted to small cluster data by Jeong (2000) as outlined in Paper III.

\subsection{Growth/evaporation: choice of solid material and condensation experiments}

Several dozens solid species have been treated in phase equilibrium in the literature (Sharp \& Huebner 1990; Fegley \& Lodders 1994). We have taken into account 12 solids $\left(\mathrm{TiO}_{2}[\mathrm{~s}], \mathrm{Al}_{2} \mathrm{O}_{3}[\mathrm{~s}]\right.$, $\mathrm{CaTiO}_{3}$ [s], $\mathrm{Fe}[\mathrm{s}], \mathrm{FeO}[\mathrm{s}], \mathrm{FeS}[\mathrm{s}], \mathrm{Fe}_{2} \mathrm{O}_{3}$ [s], $\mathrm{SiO}$ [s], $\mathrm{SiO}_{2}$ [s], $\mathrm{MgO}[\mathrm{s}], \mathrm{MgSiO}_{3}$ [s], $\mathrm{Mg}_{2} \mathrm{SiO}_{4}$ [s]) in phase-non-equilibrium to calculate the formation and composition of the dirty grains. Our selection is guided by the most stable condensates which yet have simple stoichiometric ratios that ensure that these solids can be easily built up from the gas phase. The selection covers the main element sinks during dust formation. Our choice is furthermore inspired by the following experiments.

$\mathrm{SiO}_{2}[\mathrm{~s}], \mathrm{MgO}[\mathrm{s}], \mathrm{FeO}[\mathrm{s}], \mathrm{Fe}_{2} \mathrm{O}_{3}$ [s], $\mathrm{MgSiO}_{3}[\mathrm{~s}], \mathrm{Mg}_{2} \mathrm{SiO}_{4}[\mathrm{~s}]$ :

Vapour phase condensation experiments offer strong arguments against equilibrium assemblages even under controlled conditions in the terrestrial laboratory. Rietmeijer et al. (1999) have shown that from a $\mathrm{Fe}-\mathrm{Mg}-\mathrm{SiO}-\mathrm{H}_{2} \mathrm{O}$ vapour only $\mathrm{Mg}_{x} \mathrm{Fe}_{y} \mathrm{O}_{z^{-}}$ condensates with simple stoichiometric ratios form during the condensation process in the laboratory, which is in accordance with some simple phase equilibrium calculations (e.g. Sharp \& Huebner 1990), but is in contrast to well-established textbooks like Lewis (1997). Rietmeijer et al. (1999) report on the formation of the end-member oxides $\mathrm{FeO}[\mathrm{s}], \mathrm{Fe}_{2} \mathrm{O}_{3}[\mathrm{~s}], \mathrm{MgO}[\mathrm{s}]$ and $\mathrm{SiO}_{2}[\mathrm{~s}]$, and the fosterite olivine $\mathrm{Mg}_{2} \mathrm{SiO}_{4}[\mathrm{~s}]$. The appearance of $\mathrm{SiO}_{2}$ [s] shows that kinetic factors can favour the formation of meta-stable states which is in contrast to phase equilibrium calculations.

Ferguson \& Nuth (2006) revised the vapour pressure of $\mathrm{SiO}[\mathrm{s}]$ and discuss implications for possible $(\mathrm{SiO})_{\mathrm{N}}$ nucleation. However, the experiments of Rietmeijer et al. (1999) which utilise an $\mathrm{Fe}-\mathrm{Mg}-\mathrm{SiO}-\mathrm{H}_{2} \mathrm{O}$ vapour do not show any formation of $\mathrm{SiO}$ [s]. John (2002) pointed out that $\mathrm{SiO}$ [s] formation may proceed via $\mathrm{SiO}_{2}[\mathrm{~s}]+\mathrm{Si}[\mathrm{s}] \longrightarrow 2 \mathrm{SiO}[\mathrm{s}]$. Since we are not yet able to treat solid-solid reactions, we must omit these processes in our model.

$\mathrm{Fe}[\mathrm{s}], \mathrm{FeS}[\mathrm{s}]$ : We add $\mathrm{Fe}[\mathrm{s}]$ as a high temperature condensate and $\mathrm{FeS}[\mathrm{s}]$ as possible sulphur binding solid in accordance with the experimental findings by Kern et al. (1993) and Lauretta et al. (1996).

$\mathrm{TiO}_{2}[\mathrm{~s}], \mathrm{Al}_{2} \mathrm{O}_{3}[\mathrm{~s}], \mathrm{CaTiO}_{3}[\mathrm{~s}]:\left(\mathrm{TiO}_{2}\right)_{\mathrm{N}}$ acts as a nucleation species in our model (seed particle formation). For consistency, $\mathrm{TiO}_{2}$ [s] must therefore also be included as a high-temperature solid compound to correctly account for the depletion of $\mathrm{Ti}$ from the gas phase. $\mathrm{CaTiO}_{3}[\mathrm{~s}]$ is a very stable condensate and is included to study the consumption of $\mathrm{Ca}$ from the gas phase. According to our knowledge, no laboratory measurements on $\mathrm{Ca}$-Ti oxides are available so far. The experiments by
Kern et al. (1993) suggest the formation of $\mathrm{Al}_{2} \mathrm{O}_{3}[\mathrm{~s}]$ as a hightemperature condensate.

Beckertt \& Stolper (1994) have found that by melting a $\mathrm{CaO}-\mathrm{MgO}-\mathrm{Al}_{2} \mathrm{O}_{3}-\mathrm{SiO}_{2}-\mathrm{TiO}_{2}$ system, complex compounds like $\mathrm{CaAl}_{4} \mathrm{O}_{7}, \mathrm{Ca}_{3} \mathrm{Ti}_{2} \mathrm{Al}_{2} \mathrm{Si}_{2} \mathrm{O}_{14}$ and $\mathrm{Ca}_{3} \mathrm{Al}_{2} \mathrm{Si}_{4} \mathrm{O}_{14}$ can form. It seems logic to conclude that simpler compounds like $\mathrm{MgO}$ etc. need to form before more complex compounds can be built. It might be interesting to consider Earth-crust-like solids like $\mathrm{CaSiO}_{3}$ or $\mathrm{CaCO}_{3} \cdot \mathrm{CaSiO}_{3}$ is very abundant on Earth but it forms only under high-pressure conditions inside the Earth crust at $10^{4}-10^{6}$ bar (Rossi 2006, priv. com.). $\mathrm{CaCO}_{3}$ (carbonaceous calcite), as all other carbon bearing solids, can only form in an oxygen-rich environment if the carbon is not locked into $\mathrm{CO}$ molecules. Under the high pressure conditions in brown dwarf atmospheres, this release takes place only below $\approx 800 \mathrm{~K}$ under chemical equilibrium conditions. Toppani et al. (2005) have concluded that carbonates can only form in a $\mathrm{H}_{2} \mathrm{O}(\mathrm{g})-\mathrm{CO}_{2}(\mathrm{~g})-$ rich, high-density region under conditions far away from thermal equilibrium.

Our selection of 12 solids is assumed to be formed by 60 chemical surface reactions (see Table 1). We assume for the sticking coefficient $\alpha_{r}=1$ due to the lack of data (see discussion in Paper V). The Gibbs free energy data of the solid compounds, from which the supersaturation ratios $S$ are calculated, is mostly taken from Sharp \& Huebner (1990) which were obtained for crystalline materials. The data for $\mathrm{TiO}_{2}[\mathrm{~s}]$ is given in Paper III. The new vapour pressure data for $\mathrm{SiO}$ (Ferguson \& Nuth 2006) is used. The reaction supersaturation ratios $S_{r}$ are calculated as outlined in Appendix B of Paper V.

\section{Results}

\subsection{Cloud formation and cloud structure}

The vertical structure of the dust cloud layer in a brown dwarf atmosphere is depicted in Fig. 1. The results are shown for a stellar parameter combination typically associated with the L dwarf regime.

The cloud structure results from a hierarchical dominance of nucleation (uppermost layers), growth and drift (intermediate layers), and evaporation (deepest layers). In the uppermost layers, small grains of size $\sim 0.01 \mu \mathrm{m}$ form by nucleation and grow further as they settle in the atmosphere. The particles reach a maximum size of about $200 \mu \mathrm{m}$ at the cloud base, shortly before they completely evaporate. The fall speed of the grains first decrease with increasing depth because of the increasing ambient gas densities, and then re-increase as the particles grow rapidly. Finally, they fall faster than they can grow (rain) and reach an approximately constant fall speed of a few $\mathrm{m} / \mathrm{s}$. Eventually, the grains enter the hotter atmospheric layers where they are no longer thermally stable. The grains shrink in size and dissolve into the surrounding hot and convective gas (the Schwarzschild pressure, where the atmosphere becomes convectively unstable, is 3.54 bar in this model). These results reflect the stationary character of the dust component in substellar atmospheres, where dusty material constantly forms at high altitudes and settles downward, and simultaneously, fresh uncondensed material is mixed up by convective motion and overshoot (see Ludwig et al. 2006, 2006; Young et al. 2003). These general results resemble well the results of Paper III, where only one sample dust species, $\mathrm{TiO}_{2}$ [s], was considered.

However, in comparison to Paper III, there are new features resulting from the inclusion of more than one solid growth 


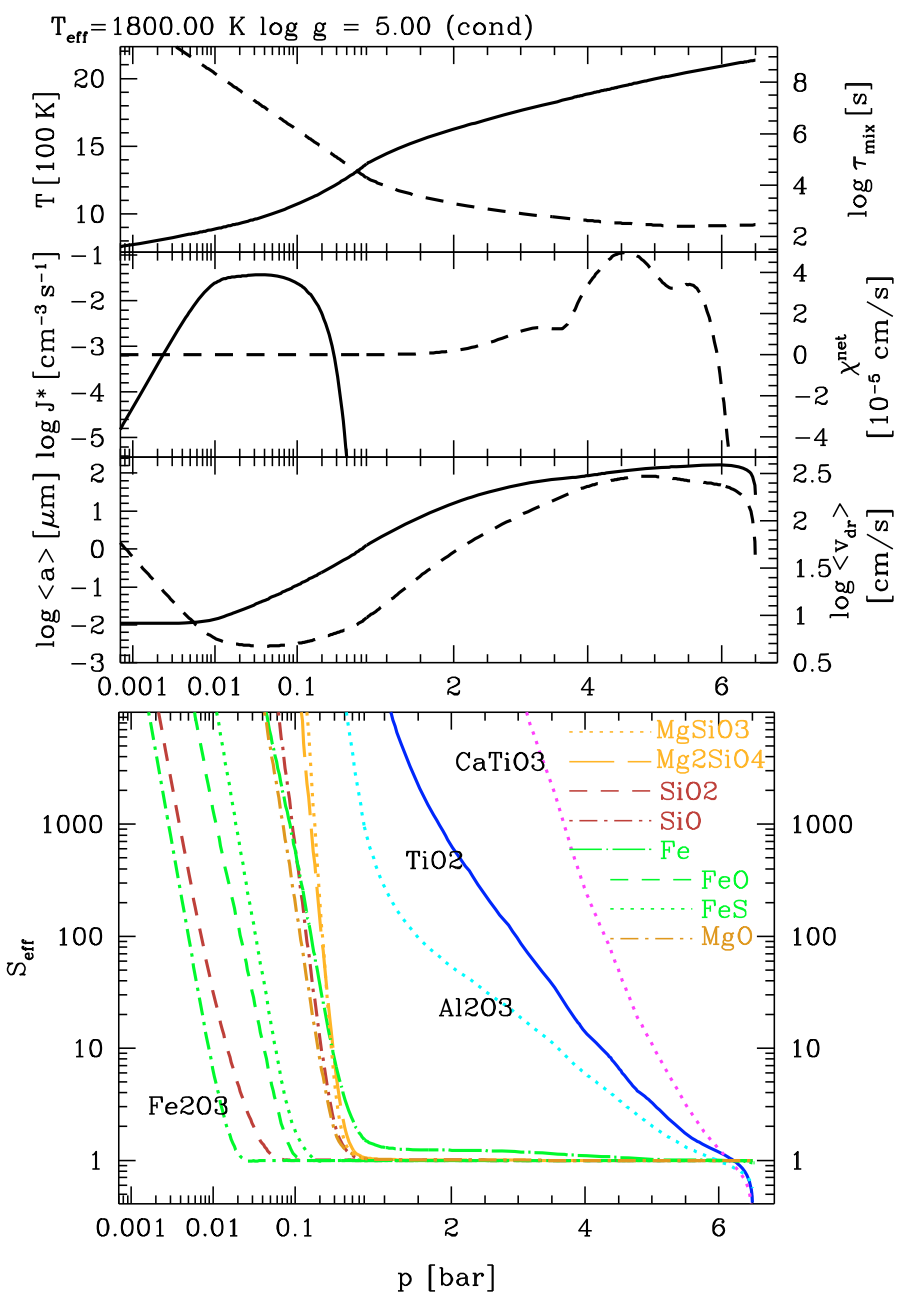

Fig. 1. Calculated cloud structure for a model with $T_{\text {eff }}=1800 \mathrm{~K}$ and $\log g=5$ (cond AMES). 1st panel: prescribed temperature $T$ (solid) and mixing time scale $\tau_{\text {mix }}$ (dashed). 2 nd panel: nucleation rate $J_{\star}$ (solid) and net growth velocity $\chi_{\text {net }}$ (dashed). $3 r d$ panel: mean grain size $\langle a\rangle=\sqrt[3]{3 /(4 \pi)} L_{1} / L_{0}$ (solid) and mean fall speed $\left\langle v_{\mathrm{dr}}^{\circ}\right\rangle=$ $\sqrt{\pi} g \rho_{\mathrm{d}}\langle a\rangle /\left(2 \rho c_{T}\right)$ (dashed). The 4 th panel depicts the effective supersaturation ratios $S_{\text {eff }}$ for all solids involved.

species and the consideration of the more abundant condensates. The net growth speed of the grains $\chi_{\text {net }}$ is never determined by a single species alone, but results from a complicated superposition where the individual contributions $\chi_{\text {net }}^{\mathrm{s}}$ can be positive (growth) or negative (evaporation). The small kinks in $\chi_{\text {net }}$ (see 2nd panel in Fig. 1) result from the evaporation of one material which becomes thermally unstable at a certain temperature, in this case $\mathrm{Mg}_{2} \mathrm{SiO}_{4}$ [s] at around $1800 \mathrm{~K}$ and $\mathrm{Fe}[\mathrm{s}]$ at around $2000 \mathrm{~K}$.

\subsection{Vapour saturation in the atmosphere}

In order to discuss deviations from phase-equilibrium, we consider the supersaturation ratio $S$, which usually indicates net growth for $S>1$ and net evaporation for $S<1$. However, for the complicated growth reactions listed in Table 1, where mostly at least 2 gas particles need to collide with the grain's surface (called "type III reactions" in Paper V), the supersaturation ratio is not unique, but reaction-dependent (see Appendix B of Paper V). In addition, the $b_{\text {surf }}^{\text {s }}$-factors are involved to account for the inequality of the active surfaces for growth and
Table 2. Typical dust volume composition $V_{\mathrm{s}} / V_{\text {tot }}$, mass composition $M_{\mathrm{s}} / M_{\mathrm{tot}}$, and mean particles sizes $\langle a\rangle[\mu \mathrm{m}]$ as a function of local temperature for models as depicted in Fig. 2. ( $\nearrow$ - increasing in $T$-interval; (\)-decreasing in $T$-interval.

\begin{tabular}{|c|c|c|c|}
\hline $\begin{array}{r}T \\
{[\mathrm{~K}]}\end{array}$ & $V_{\mathrm{s}} / V_{\mathrm{tot}}$ & $M_{\mathrm{s}} / M_{\mathrm{tot}}$ & $\begin{array}{l}\langle a\rangle \\
{[\mu \mathrm{m}]}\end{array}$ \\
\hline $\begin{array}{r}700 \\
.\end{array}$ & $\begin{array}{l}24 \% \mathrm{MgSiO}_{3}, 20 \% \mathrm{Mg}_{2} \mathrm{SiO}_{4} \\
12 \% \mathrm{SiO}_{2}, 10 \% \mathrm{SiO}, 9 \% \mathrm{FeS} \\
\left\{\mathrm{MgO}, \mathrm{FeO}, \mathrm{Fe}_{2} \mathrm{O}_{3}\right\}<9 \% \\
\left\{\mathrm{Fe}, \mathrm{Al}_{2} \mathrm{O}_{3}\right\}<5 \%\end{array}$ & $\begin{array}{l}\text { 1. } \mathrm{MgSiO}_{3} \\
\text { 2. } \mathrm{Mg}_{2} \mathrm{SiO}_{4} \\
\text { 3. } \mathrm{FeS}, \mathrm{Fe}_{2} \mathrm{O}_{3}, \mathrm{FeO} \\
\text { 4. } \mathrm{SiO}_{2}, \mathrm{MgO}, \mathrm{Fe}\end{array}$ & $\begin{array}{l}10^{-3} \\
\cdot \\
.\end{array}$ \\
\hline $\begin{array}{l}950 \\
950\end{array}$ & $\left\{\mathrm{TiO}_{2}, \mathrm{CaTiO}_{3}\right\}<1 \%$ & 5. $\mathrm{SiO}$ & $\begin{array}{l}10^{-2} \\
10^{-2}\end{array}$ \\
\hline 1200 & \multicolumn{2}{|c|}{ strongly changing } & $10^{-0.5}$ \\
\hline 1200 & $\begin{array}{l}35 \% \mathrm{Mg}_{2} \mathrm{SiO}_{4}, 23 \% \mathrm{SiO}_{2} \\
<20 \% \mathrm{MgSiO}_{3}(\searrow) \\
15 \% \mathrm{Fe}, 5 \% \mathrm{MgO}\end{array}$ & $\begin{array}{l}\text { 1. } \mathrm{Fe} \\
\text { 2. } \mathrm{Mg}_{2} \mathrm{SiO}_{4} \\
\text { 3. } \mathrm{SiO}_{2} / \mathrm{MgSiO}_{3}\end{array}$ & $\begin{array}{l}10^{-0.5} \\
\cdot \\
.\end{array}$ \\
\hline $\begin{array}{l}1700 \\
1700\end{array}$ & everything else $<5 \%$ & 4. $\mathrm{MgO}$ & $\begin{array}{l}10 \\
10\end{array}$ \\
\hline 1900 & $\begin{array}{r}\text { strongly chan } \\
\text { (SiO, MgO peaking }\end{array}$ & $\begin{array}{l}\text { ging } \\
\text { but low \%) }\end{array}$ & $10^{2}$ \\
\hline $\begin{array}{r}1900 \\
2100\end{array}$ & $\begin{array}{l}72 \% \mathrm{Fe}(\searrow) \\
20 \% \mathrm{Al}_{2} \mathrm{O}_{3}(\nearrow),<5 \% \mathrm{TiO}_{2} \\
\left.10 \% \mathrm{CaTiO}_{3} \text { (at } 2100 \mathrm{~K}\right)\end{array}$ & $\begin{array}{l}\text { 1. } \mathrm{Fe} \\
\text { 2. } \mathrm{Al}_{2} \mathrm{O}_{3}(\nearrow) \\
\text { 3. } \mathrm{CaTiO}_{3}\end{array}$ & $\begin{array}{l}10^{2} \\
(\star) \\
0\end{array}$ \\
\hline
\end{tabular}

$(\star)$ Mean grain sizes $\langle a\rangle$ can reach up to $10^{3.5}$ in lower gravity atmospheres like giant-gas planets (compare Fig. 4).

evaporation (see Paper V). The thermal stability of the solids is then better defined by $\chi_{\text {net }}^{\mathrm{s}}=0$ (see Eq. (4)). In order to discuss the saturation of the atmosphere, we define a unique effective supersaturation ratio $S_{\text {eff }}$ for each solid as

$$
\begin{aligned}
& \sum_{r=1}^{R}\left(1-\frac{1}{S_{r} b_{\text {surf }}^{\mathrm{s}}}\right) \frac{\Delta V_{r}^{\mathrm{s}} n_{r}^{\mathrm{key}} \mathrm{v}_{r}^{\mathrm{rel}} \alpha_{r}}{v_{r}^{\mathrm{key}}}= \\
& \left(1-\frac{1}{S_{\text {eff }}^{\mathrm{s}} b_{\text {surf }}^{\mathrm{s}}}\right) \sum_{r=1}^{R} \frac{\Delta V_{r}^{\mathrm{s}} n_{r}^{\mathrm{key}} \mathrm{v}_{r}^{\mathrm{rel}} \alpha_{r}}{v_{r}^{\mathrm{key}}} .
\end{aligned}
$$

These effective supersaturation ratios $S_{\text {eff }}$ shown in Fig. 1 (4th panel) demonstrate that none of the considered solids obeys the condition of phase-equilibrium $\left(S_{\text {eff }}=1\right)$ throughout the entire cloud layer in our model. In particular, the atmospheric gas is strongly supersaturated in the uppermost layers where the nucleation takes place. However, in contrast to $\mathrm{TiO}_{2}$ [s] discussed in Paper III, the more abundant silicates and iron compounds reach a state of quasi-phase-equilibrium $\left(S_{\text {eff }} \gtrsim 1\right)$ already at $p=$ $0.05 \ldots 1$ bar whereas the rare condensates like $\mathrm{TiO}_{2}[\mathrm{~s}], \mathrm{Al}_{2} \mathrm{O}_{3}[\mathrm{~s}]$, and $\mathrm{CaTiO}_{3}[\mathrm{~s}]$ practically never obey the phase-equilibrium condition. This behaviour is caused by the different element depletion time scales being longest for the low abundant elements as we have demonstrated in Paper V (Sect. 4.4.3.). Since the observable molecular features are typically formed high in the atmosphere and even the broad dust features in the wavelength region $7-20 \mu \mathrm{m}$ originate from layers $p \approx 0.2 \ldots 0.6$ bar in this model (see Sect. 5.2), we conclude that the observable dust in brown dwarf atmospheres in not in phase-equilibrium with the gas.

\subsection{Chemical composition of the cloud particles}

The chemical composition of the dust grains is expressed by the solid material volume fractions $V_{\mathrm{s}} / V_{\text {tot }}$ (Fig. 2, top panel) and 

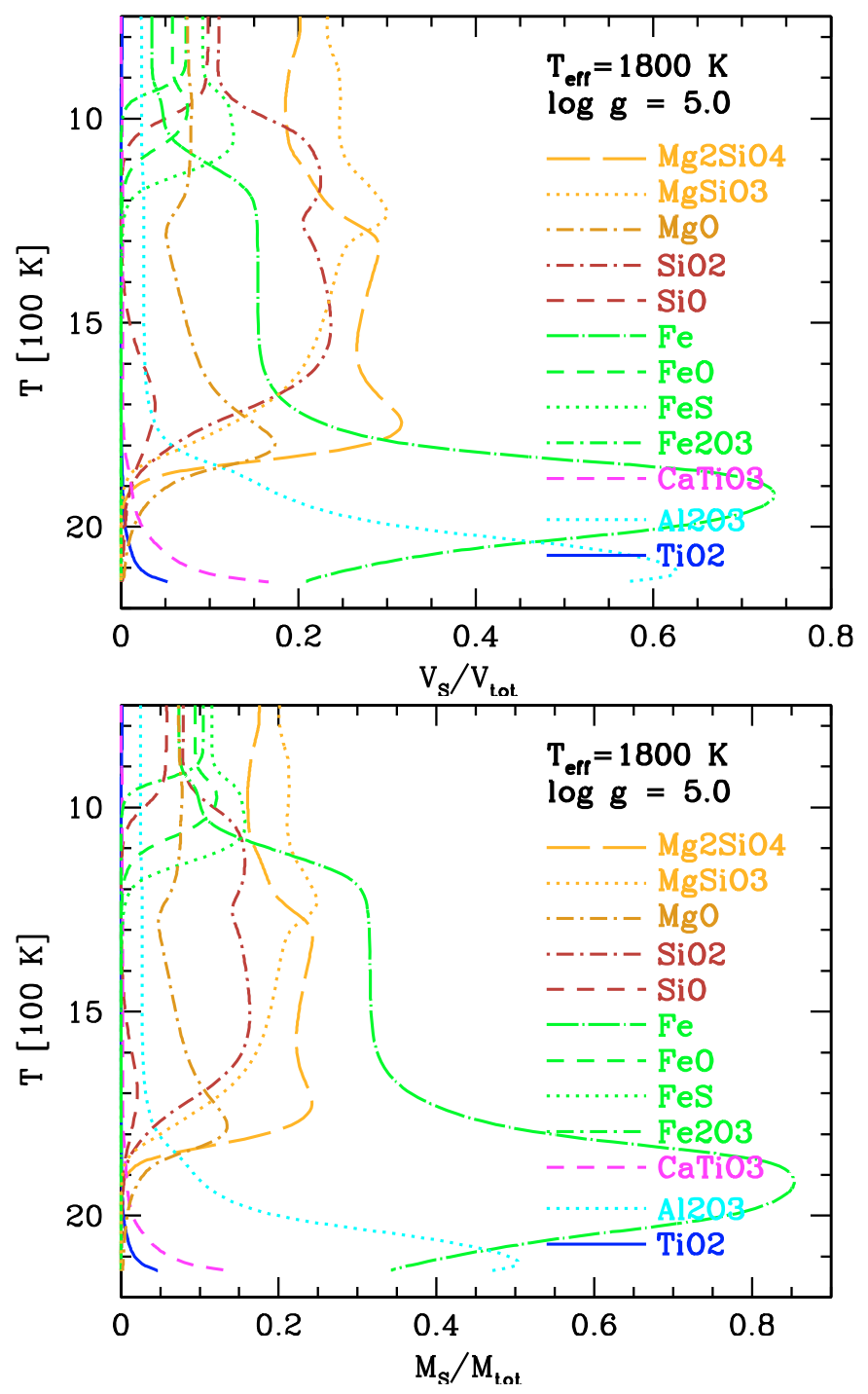

Fig. 2. Volume fractions $V_{\mathrm{s}} / V_{\text {tot }}$ (top) and mass fractions $M_{\mathrm{s}} / M_{\mathrm{tot}}$ (bottom) of the various solid compounds for the model depicted in Fig. 1. The temperature scale follows the atmospheric stratification, being cool at the top and hot at the bottom.

mass fractions $M_{\mathrm{s}} / M_{\mathrm{tot}}=V_{\mathrm{s}} \rho_{\mathrm{s}} /\left(V_{\mathrm{tot}} \rho_{\mathrm{d}}\right)$ (lower panel). The dust material composition is mainly controlled by the temperature, and shows a constantly re-occurring pattern in models with different stellar parameter for brown dwarfs and gas giant-planets (see also Table 2). Once a solid becomes thermally unstable, the respective elements evaporate into the gas, making them available again to form other, more stable condensates. In this way, we find a complicated mix of all condensates high in the atmosphere with volume fractions resulting from kinetic constraints that favour the formation of the more abundant silicates and $\mathrm{Fe}$ oxides. As these dirty particles settle in the atmosphere they stepwise purify, until only the most stable component parts like $\mathrm{Al}_{2} \mathrm{O}_{3}$ [s], $\mathrm{Fe}[\mathrm{s}]$, and $\mathrm{CaTiO}_{3}$ [s] remain.

Therefore, two classes of solids can be distinguished: the high-temperature condensates $\mathrm{Fe}[\mathrm{s}]$ and $\mathrm{Al}_{2} \mathrm{O}_{3}[\mathrm{~s}]$ with some contributions of $\mathrm{Ca}$-Ti-oxides in the deeper layers, and the medium-temperature condensates $\mathrm{MgSiO}_{3}[\mathrm{~s}], \mathrm{Mg}_{2} \mathrm{SiO}_{4}[\mathrm{~s}]$ and $\mathrm{SiO}_{2}[\mathrm{~s}]$ with some $\mathrm{SiO}[\mathrm{s}]$ and $\mathrm{FeS}[\mathrm{s}]$ in the upper layers.

As the temperature increases, $\mathrm{SiO}[\mathrm{s}]$ starts to evaporate and $\mathrm{SiO}_{2}[\mathrm{~s}]$ becomes the second most abundant solid material by
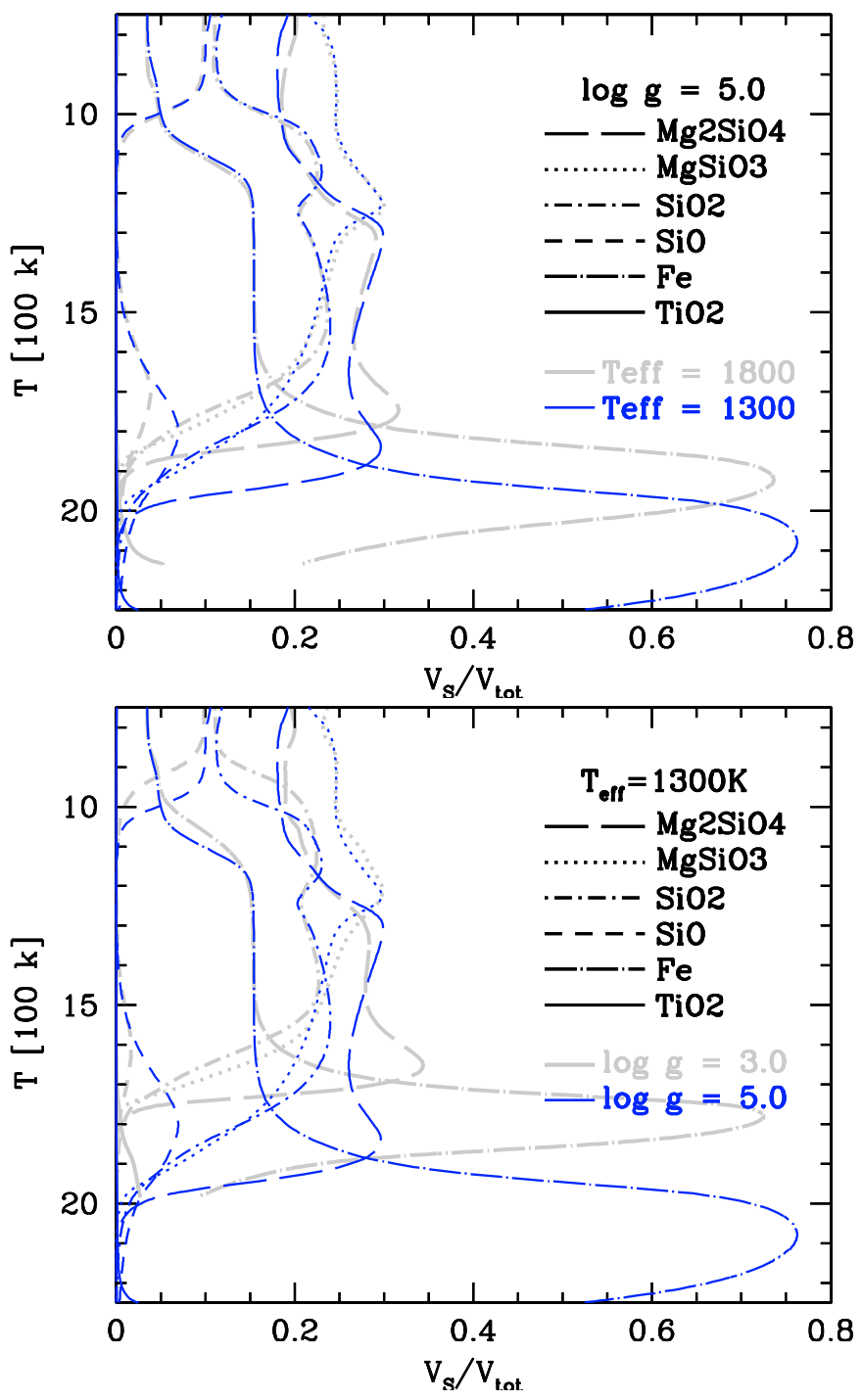

Fig. 3. Volume fractions $V_{\mathrm{s}} / V_{\text {tot }}$ for different $T_{\text {eff }}$ (top) and different $\log g$ (bottom). Only the more abundant solid compounds are viewed, in contrast to Fig. 2.

volume fraction. Next, $\mathrm{MgSiO}_{3}[\mathrm{~s}]$ evaporates which sets free some $\mathrm{Mg}$ and $\mathrm{Si}$ to form more $\mathrm{Mg}_{2} \mathrm{SiO}_{4}[\mathrm{~s}]$ and $\mathrm{SiO}_{2}[\mathrm{~s}]$, making $\mathrm{SiO}_{2}[\mathrm{~s}]$ again the second most abundant solid. The transition from the medium-temperature to the high-temperature composition is characterised by the evaporation of $\mathrm{Mg}_{2} \mathrm{SiO}_{4}[\mathrm{~s}]$, which leaves only $\mathrm{Fe}[\mathrm{s}], \mathrm{Al}_{2} \mathrm{O}_{3}[\mathrm{~s}], \mathrm{TiO}_{2}$ [s] and $\mathrm{CaTiO}_{3}[\mathrm{~s}]$ as stable condensates. As Fe[s] evaporates, the cloud base is soon reached where eventually the remaining Al-Ca-Ti oxides evaporate.

The volume fractions are important for the dust opacities (see Sect. 5), and in the observable layers the Mg-silicates turn out to be the most relevant condensates. For completeness we note, however, that the mass fraction $M_{\mathrm{s}} / M_{\text {tot }}$ is dominated by Fe[s] from about $1200 \mathrm{~K}$ to $2000 \mathrm{~K}$.

We recognise that the chemical composition of the dust grains does to some extent depend on the completeness of the selection of solids and on the availability of material quantities (e.g. the sticking coefficients as shown in Sect. 4.6. in Paper V). For example, the partial volume of $\mathrm{Mg}_{2} \mathrm{SiO}_{4}[\mathrm{~s}]$ and $\mathrm{MgSiO}_{3}[\mathrm{~s}]$ decreases if $\mathrm{MgO}[\mathrm{s}]$ is included, and the partial volume of $\mathrm{SiO}_{2}[\mathrm{~s}]$ decreases if $\mathrm{SiO}[\mathrm{s}]$ is included. For this reason, 


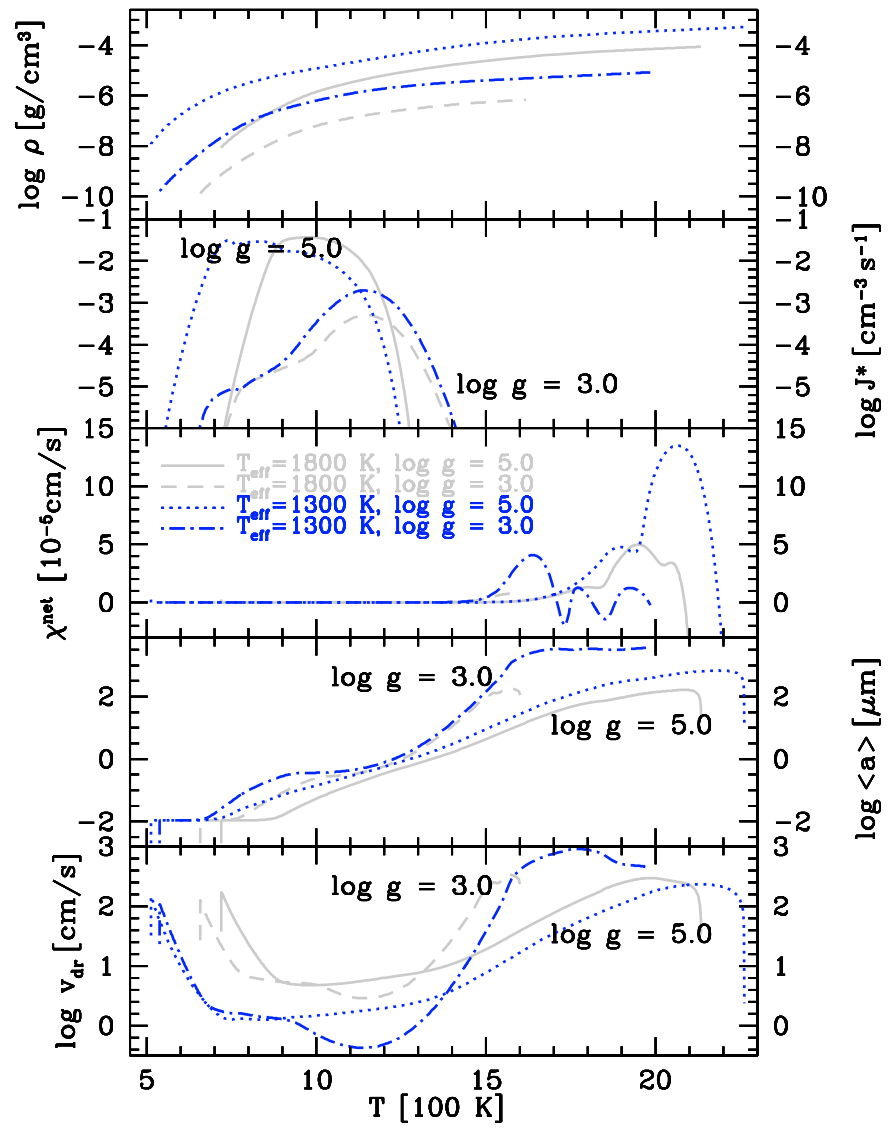

Fig. 4. Comparison of results for different stellar parameter. 1st box: mass density $\rho$, 2nd box: nucleation rate $J_{\star}, 3$ rd box: net growth velocity $\chi^{\text {net }} 4$ th box: mean particle size $\langle a\rangle$, 5th box: mean fall speed $\left\langle\dot{v}_{\mathrm{dr}}\right\rangle$. All quantities are plotted as function of temperature $T$. Dotted line: $T_{\text {eff }}=1300 \mathrm{~K}, \log g=5$; solid line: $T_{\text {eff }}=1800 \mathrm{~K}, \log g=5$; dash-dotted line: $T_{\mathrm{eff}}=1300 \mathrm{~K}, \log g=3$; dashed line: $T_{\mathrm{eff}}=1800 \mathrm{~K}$, $\log g=3$.

the partial volume of $\mathrm{SiO}_{2}[\mathrm{~s}]$ is smaller than described in Helling et al. (2006).

\subsection{Dependence on $T_{\text {eff }}$ and $\log g$}

Figure 3 shows the dependence of the dust material composition on $T_{\text {eff }}$ and $\log g$. If plotted against temperature, the volume fractions show a robust pattern for all calculated models (see Table 2). Only a slight shift to higher temperatures (deeper layers) can be noticed for lower $T_{\text {eff }}$ (upper plot) and higher $\log g$ (lower plot).

An increase of $\log g$ results in a more compact atmosphere, i.e. generally higher pressures in the atmosphere. Since the dust sublimation temperatures increase with increasing pressure, the dust remains stable to even higher temperatures for larger $\log g$. For the same reason, models with lower $T_{\text {eff }}$ show dust at comparably higher temperatures. For lower $T_{\text {eff }}$, a certain temperature is reached deeper inside the atmosphere, where the pressure is higher and, hence, the dust is more stable.

Figure 4 shows the dependence of the nucleation rate, the mean particle size and the mean fall speed on $T_{\text {eff }}$ and $\log g$. The nucleation zone typically lies between $600 \mathrm{~K}$ and $1400 \mathrm{~K}$ in all models. The maximum rate reaches higher values for higher $\log g$ because of the higher gas densities. For lower $\log g$, the nucleation maximum is more extended and shows a more
Table 3. Maximum dust-to-gas ratio and temperature interval where the dust-to-gas ratio is larger than half maximum.

\begin{tabular}{cccc}
\hline \hline$T_{\text {eff }}[\mathrm{K}]$ & $\log g$ & $\left(\frac{\rho_{\mathrm{d}}}{\rho_{\text {gas }}}\right)_{\max }\left[10^{-3}\right]$ & Temp. interval $[\mathrm{K}]$ \\
\hline 1300 & 5 & 2.6 & $1300-1800$ \\
1800 & 5 & 2.6 & $1300-1800$ \\
2200 & 5 & 2.1 & $1450-1750$ \\
2500 & 5 & 0.2 & $1550-1800$ \\
1300 & 3 & 4.0 & $950-1600$ \\
1800 & 3 & 3.8 & $1000-1600$ \\
2200 & 3 & 2.3 & $1300-1500$ \\
2500 & 3 & 0.04 & $1550-1700$ \\
\hline
\end{tabular}

complicated shape that is probably caused by the closer neighbourhood to the convective zone, which makes the up-mixing of fresh elements for nucleation more likely.

Concerning the mean particle size, all models show about the same small particles of order $0.01 \mu \mathrm{m}$ high in the atmosphere, which grow to large particles between about $100 \mu$ and $1000 \mu$ in the deep layers. The maximum particle sizes reached at cloud base are larger for lower $\log g$. As the nucleation zone ends, there is a zone of rapid grain growth around $1400 \mathrm{~K}$ to $1700 \mathrm{~K}$. In this zone, most of the solid particles are actually "mixed away" according to our simple approach to treat the mixing by convective motion and overshoot. The small number of particles that stay, however, settle deeper into a denser environment where elements are mixed with higher efficiency due to the decreasing distance from the convection zone. The models show that this small number of growing particles is sufficient to maintain a state close to phase equilibrium with the gas for most elements, i.e. the growth is exhaustive. Thereby, the particles grow further along their way down the atmosphere while their number is ever decreasing due to lethal mixing.

The growth of the particles, however, is limited by their own fall speed which increases with size. The grains eventually reach a size where their residence time is so small that further growth becomes negligible. The residence time scale $\tau_{\text {sink }}=\stackrel{\circ}{v}_{\mathrm{dr}} / H_{p}$, however, depends on the atmospheric scale height $H_{p}$ which is 100 times larger for the $\log g=3$ models. Therefore, the dust particles have more time to grow in the low log $g$ models, producing larger sizes and larger fall speeds.

We note that the Knudsen numbers fall short of unity in the deeper layers, for particles larger than about $1 \mu \mathrm{m}$ in the $\log g=5$ models and about $10 \mu \mathrm{m}$ in the $\log g=3$ models. This means, that the frictional force and the growth velocity should be calculated for the case of small Knudsen numbers in the deeper layers, making necessary a Knudsen number fall differentiation (see Paper II for details). Therefore, the results of this paper concerning the particle sizes in the deeper layers must be taken with care. The true fall speeds are probably higher there and the true growth velocities are probably smaller than our results, i.e. we expect that $\langle a\rangle$ remains smaller in the deeper layers compared to Fig. 4.

\subsection{Dust-to-gas ratio}

Figure 5 shows the dust-to-gas mass ratios $\rho_{\mathrm{d}} / \rho_{\text {gas }}$ and the dust mass column densities $M_{\text {dust }}=\int \rho_{\mathrm{d}} \mathrm{d} z\left[\mathrm{~g} / \mathrm{cm}^{2}\right]$ as a function of pressure. The dust-to-gas ratio generally first increases inward log-linear, then reaches a plateau and finally decreases rapidly as the dust becomes thermally unstable. The upper plot shows 

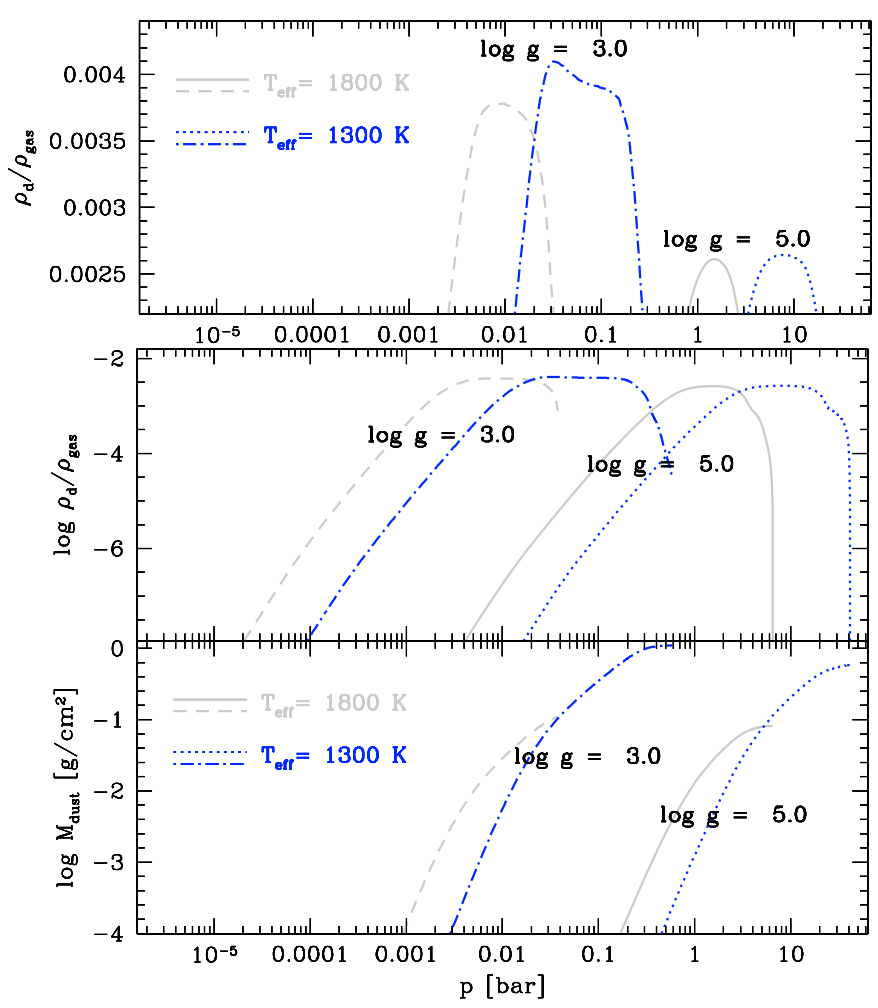

Fig. 5. Dust-to-gas mass ratios $\rho_{\mathrm{d}} / \rho_{\text {gas }}$ and dust mass column densities $M_{\text {dust }}$ for brown dwarf and giant-planets atmospheres. 1st panel: linear plot, 2nd panel: logarithmic plot. Dotted line: $T_{\mathrm{eff}}=1300 \mathrm{~K}, \log g=5$; solid line: $T_{\text {eff }}=1800 \mathrm{~K}, \log g=5$; dash-dotted line: $T_{\text {eff }}=1300 \mathrm{~K}$, $\log g=3$; dashed line: $T_{\text {eff }}=1800 \mathrm{~K}, \log g=3$.

the same quantities on a linear scale, further emphasising the truly dusty layers.

For the four models depicted in the previous figures, the dust-to-gas ratio reaches a constant maximum value between about $0.25 \%$ and $0.4 \%$ in a temperature interval $T \in[(1000-1300) \mathrm{K} \ldots$... (1600-1800) K] rather independent of $T_{\text {eff }}$, where the temperature interval boundaries increase with increasing $\log g$ (see Sect. 4.4). The width of the dusty temperature window is about $500 \mathrm{~K}$ to $600 \mathrm{~K}$ for the depicted models with $T_{\text {eff }}=1300 \mathrm{~K}$ and $1800 \mathrm{~K}$ (compare Table 3 ). This result is consistent with the simple dust approach made by Tsuji (2002), although the window is broader than assumed by Tsuji according to our findings. Similar maximum values are found even if we increase $T_{\text {eff }}$ to $2200 \mathrm{~K}$. However, if we increase $T_{\text {eff }}$ further to $2500 \mathrm{~K}$, the maximum dust-to-gas ratio drops by more than one order of magnitude (see Table 3 ). We conclude that $T_{\text {eff }} \approx 2200 \mathrm{~K}$ is the threshold value for truly dust-rich layers to occur in the models presented here.

The resulting dust-to-gas ratios demonstrate that the cloud layer is primarily attached to the local temperature. For lower $T_{\text {eff }}$, the dust layer sinks deeper into the atmosphere and eventually disappears from the observable layers. Since the dust is then present in denser regions, the dust mass column density $M_{\text {dust }}$ increases.

\subsection{Remaining gas-phase chemistry and metallicity}

The remaining gas-phase composition depends on the amount of elements not locked up into dust grains. As a result of our model, phase-equilibrium is not valid in the upper layers (see

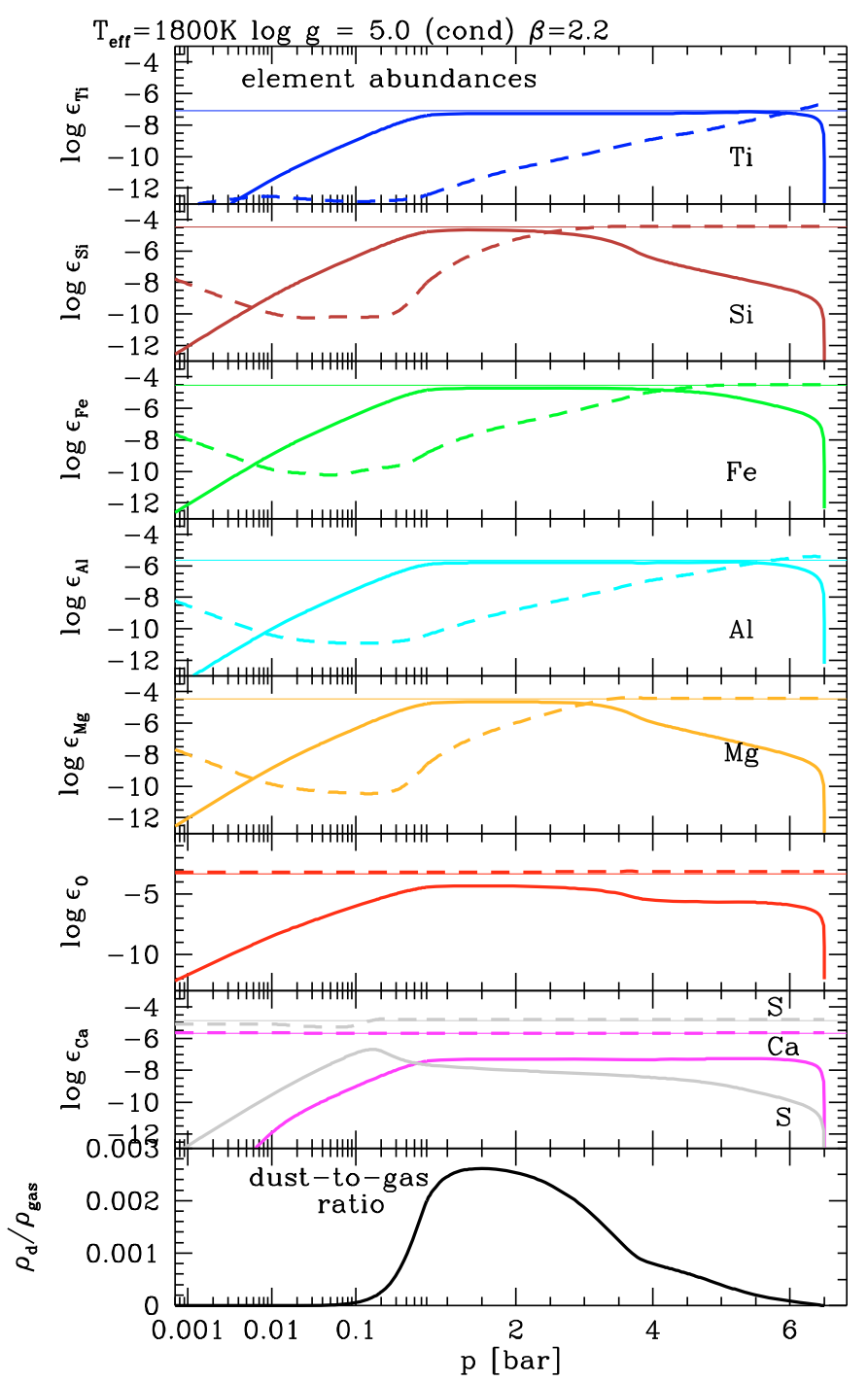

Fig. 6. Element abundances in dust $\epsilon_{\mathrm{d}}$ (thick solid) and in the gas phase $\epsilon_{\mathrm{i}}$ (dashed). The solar values $\epsilon_{\mathrm{i}, \text { Sun }}$ (thin solid) and the linear dust-togas ratio $\rho_{\mathrm{d}} / \rho_{\text {gas }}$ (lowest panel) are shown for comparison. The stellar parameters are $T_{\text {eff }}=1800 \mathrm{~K}$ and $\log g=5$ as in Fig. 1 .

Fig. 1, 4th panel) and should not be used to determine gas particle abundances. The remaining gas abundances $\epsilon_{\mathrm{i}}$ are strongly sub-solar in an extended layer above the cloud layer where the pressure drops by about 3 orders of magnitude (about 10 scale heights), see Figs. 6 and 7. Inside the cloud layer, the metal abundances increase with increasing atmospheric depth and finally reach even slightly larger than solar values at the cloud base, where those elements that have been locked up in grains in the upper layers are released by evaporation.

Figure 6 shows this phase lag between metal gas abundances and dust abundances clearly. Considering a path from the top to the bottom of the atmosphere, first the metals disappear, then the dust appears, then the metals reappear and finally the dust disappears (the sum of dust and gas abundances is not constant).

The calculation of the gas phase element abundances allows for a discussion of the metallicity in dust forming atmospheres (see Fig. 7), i.e. the logarithmic differences of the gas abundances with respect to the solar values. The metallicities are not the same - not even similar - for different elements. The strongest depletions occur for $\mathrm{Ti}, \mathrm{Mg}$ and $\mathrm{Si}$, for which 


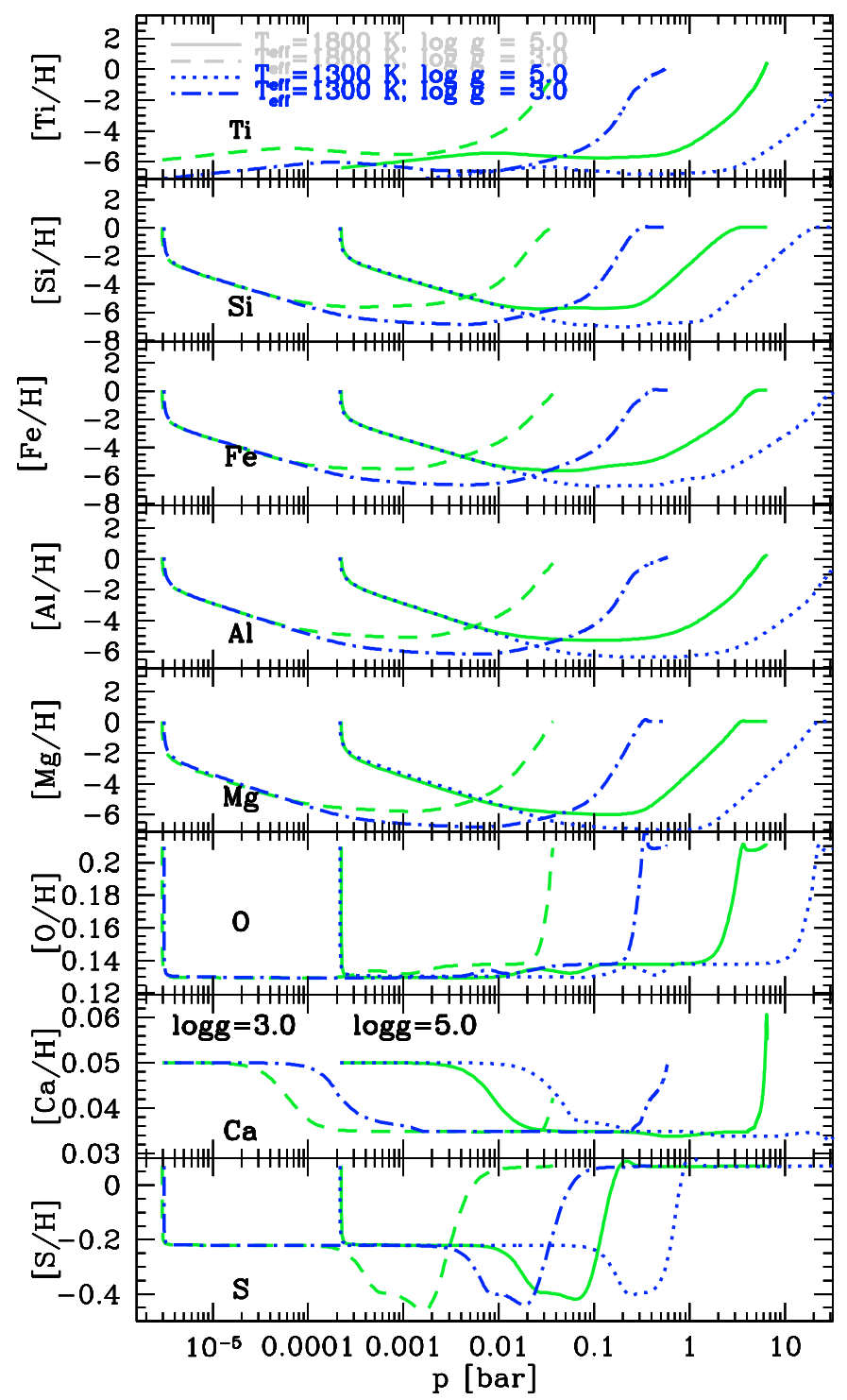

Fig. 7. Element abundances involved in the dust formation process for two effective temperatures and two different gravities. Dotted blue: $T_{\text {eff }}=1300 \mathrm{~K}, \log g=5$; solid green: $T_{\text {eff }}=1800 \mathrm{~K}, \log g=5$; dashdotted blue: $T_{\text {eff }}=1300 \mathrm{~K}, \log g=3$; dashed green: $T_{\text {eff }}=1800 \mathrm{~K}$, $\log g=3$.

the metallicities reach values as low as -6 to -7 . The depletion of $\mathrm{S}$ and $\mathrm{Ca}$ is much less significant $(>-0.5)$ in comparison. Concerning $\mathrm{Ca}$, this is questionable because it is due to our limited choice of solids. There is only one $\mathrm{Ca}$ bearing solid species considered, $\mathrm{CaTi}_{3}[\mathrm{~s}]$, and since $\mathrm{Ti}$ is less abundant than $\mathrm{Ca}, \mathrm{Ca}$ cannot be locked up completely into grains. It is important to note, however, that according to our models, the gas depletion factors are kinetically limited by a maximum factor of about $10^{6}$. Larger depletion factors simply cannot occur because the depletion timescale (see Paper V) would exceed the mixing timescale. In contrast, complete phase equilibrium would imply that the depletion factors can reach values as high as $10^{50}$ for low temperatures. Figure 7 also demonstrates that the metallicities change with altitude and depend on the stellar parameter.

A special feature of our models is that the metal abundances in the gas phase re-increase high above the cloud layer. In our model, all elements are constantly mixed upward, and although the mixing timescale is as long as $\tau_{\text {mix }}=10^{10} \mathrm{~s}$ in the highest layers, the timescale for a gaseous particle to find a surface to condense on exceeds this timescale, because the dust abundance drops steeply above the cloud layer. Consequently, the metal abundances asymptotically re-approach the solar values high above the cloud layer. The only exception is Ti, which can disappear from the gas phase via nucleation. This feature distinguishes our models from all other published models, and might open up a possibility to discriminate between the models by detailed line profile observations of neutral alkali and alkaline earth metal atoms. Our dust treatment results in deeper and broader resonance lines of $\mathrm{NaI}$, and $\mathrm{KI}$ in the red part of the spectrum, which form high in the atmosphere (Johnas et al. 2007).

\subsection{Grain size distribution}

In Fig. 8 we show the results for the potential exponential grain size distribution function $f(a, z)\left[\mathrm{cm}^{-4}\right]$ (see Appendix A.2) with parameters derived from the calculated dust moments $L_{\mathrm{j}}(z)$. The altitudes have been selected arbitrarily throughout the entire dust cloud for visualisation.

The evolution of the grain size distribution through the cloud layer is similar for models with the same $\log g$. Considering the $\log g=5$ models (upper row in Fig. 8), the size distribution starts relatively broadly in the upper atmosphere where the nucleation is active, because the constant creation and simultaneous growth of the particles causes a broad distribution. Once the nucleation ceases, however, all particles merely shift in size space by a constant offset $\Delta a$ due to further growth, which means a narrowing in $\Delta(\log a)$. Since the particles grow by more than 4 orders of magnitude on their way down the atmosphere, the size distribution finally becomes strongly peaked.

In the $\log g=3$ models (lower panel in Fig. 8), the evolution of the size distribution function is more complicated. As shown in Fig. 4, the nucleation rate has a small shoulder as function of pressure on the left hand side. This feature leads to a narrowing of $f(a)$ at first, followed by a re-widening of the size distribution function with increasing depth. The nucleation zone is closer to the convective zone and sometimes even overlaps with the convective zone in the $\log g=3$ models. Therefore, although the nucleation rate becomes tiny with increasing depth, it does not vanish completely until about $1600 \mathrm{~K}$ which still influences the size distribution and keeps it broad.

\section{Simple radiative transfer modelling}

\subsection{Model description}

We simulate the grain absorption features in two brown dwarf atmosphere cases $\left(T_{\text {eff }}=1800 \mathrm{~K}, \log g=5\right.$ and $T_{\text {eff }}=1300 \mathrm{~K}$, $\log g=5)$ and one example of a giant-gas planet atmosphere $\left(T_{\text {eff }}=1300 \mathrm{~K}, \log g=3\right.$ ) using a simple radiative transfer code. The code considers the solid-state opacities similar to Helling et al. (2006) ${ }^{3}$. Grain opacities are calculated according to their size distribution $f(a, z)\left[\mathrm{cm}^{-4}\right]$ and their solid material volume composition $V_{\mathrm{s}}(z)$ (Figs. 2, 8) using the effective medium theory according to Bruggeman (1935) to calculate the effective optical constants and Mie theory for spherical particles to calculate the extinction efficiencies $Q_{\text {ext }}(a, \lambda)$. The main difference between the previous code and the present one is that the grains are here assumed to be distributed according to the potential exponential

\footnotetext{
3 More complex methods applicable to hydrodynamic environments are given in e.g. Helling \& Jørgensen (1998) and Woitke (2006).
} 

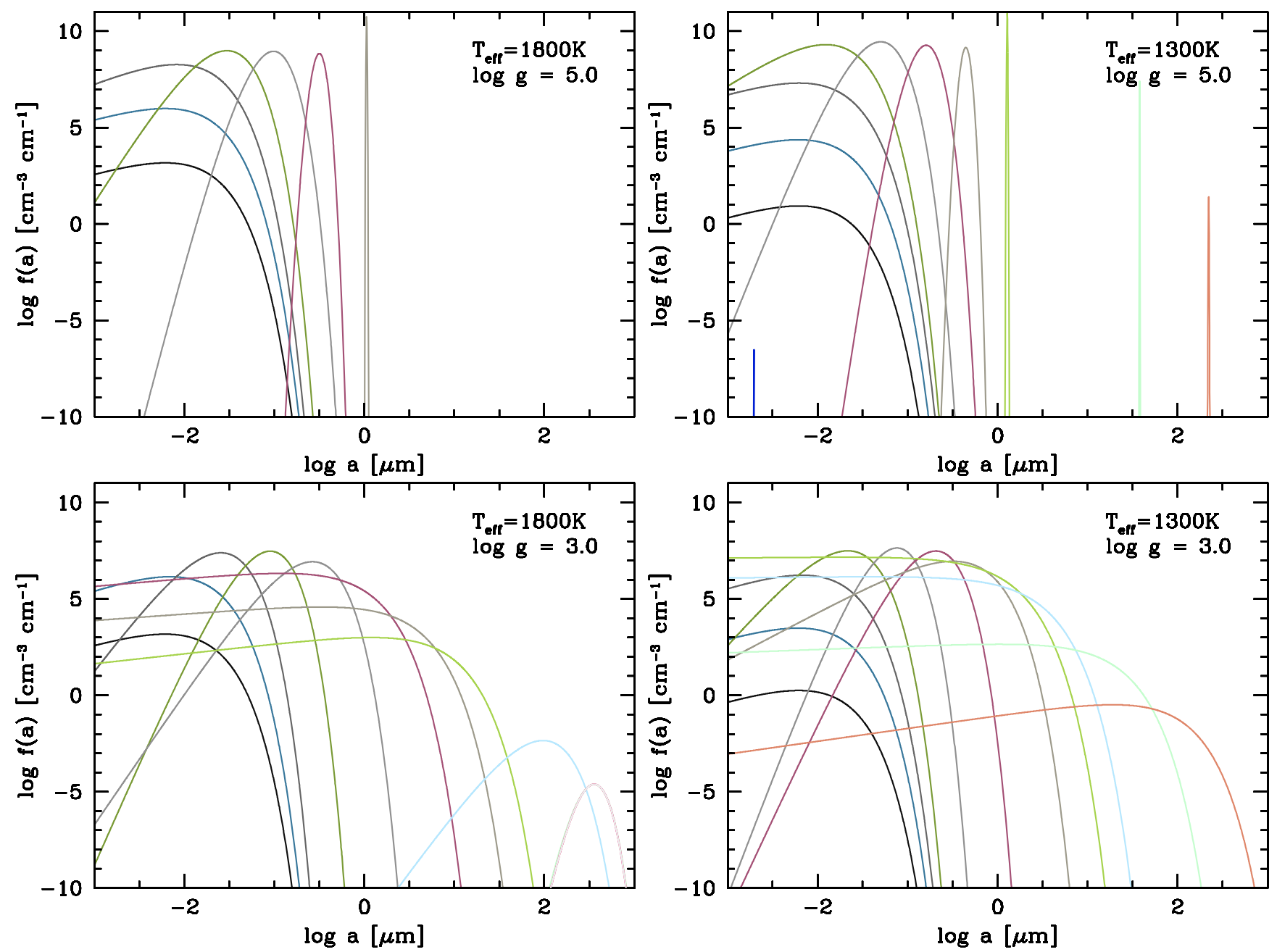

Fig. 8. Grain size distribution function $f(a, z)\left[\mathrm{cm}^{-4}\right]$ for a number of selected cloud altitudes. The broad distributions on the lhs of all plots correspond to high altitudes. In the left upper figure, the deeper distributions are very close to a $\delta$-function and not presentable anymore.

size distribution function (see Appendix A.2) determined from the calculated dust moments at height $z$, whereas in the previous model a $\delta$-function, $f(a, z)=\rho L_{0}(z) \delta(a-\langle a\rangle(z))$ representing the mean particle size $\langle a\rangle$, was assumed. The present code includes the 12 solid species discussed in the previous sections (see Table 4 for the references for the optical constants). The total grain extinction cross-section (see inner integral in Eq. (13)) is computed using a Gauss-Legendre quadrature integration over the entire grain size distribution function at a given atmospheric height.

We examine the radiation transfer in the $7 \mu \mathrm{m}$ to $20 \mu \mathrm{m}$ wavelength range, which encompasses the $\mathrm{Si}-\mathrm{O}$ stretching mode (centred at $9.7 \mu \mathrm{m}$ ) and $\mathrm{Si}-\mathrm{O}$ bending mode (around $18 \mu \mathrm{m}$ ) of crystalline silicates $\left(\mathrm{Mg}_{2} \mathrm{SiO}_{4}\right.$ and $\left.\mathrm{MgSiO}_{3}\right)$ and quartz $\left(\mathrm{SiO}_{2}\right)$. The model calculates the optical depth of the dust component as

$\tau_{\lambda}^{\text {dust }}(z)=\int_{0}^{z} \int_{0}^{\infty} f\left(a, z^{\prime}\right) \pi a^{2} Q_{\text {ext }}\left(a, \lambda, V_{\mathrm{s}}\left(z^{\prime}\right)\right) \mathrm{d} a \mathrm{~d} z^{\prime}$

and determines the geometrical depth $z_{0}(\lambda)$ where $\tau_{\lambda}^{\text {dust }}\left(z_{0}\right)=1$ for each wavelength. Furthermore, we replace the opacity of the solid species by vacuum to estimate their respective effects on the output spectrum. To calculate the transmission spectra (first
Table 4. Reference for the optical constant of amorphous materials used in the radiative transfer modelling.

\begin{tabular}{ll}
\hline \hline Solid species & Reference \\
\hline $\mathrm{TiO}_{2}[\mathrm{~s}]$ & Ribarsky et al. (1985) \\
$\mathrm{SiO}_{2}[\mathrm{~s}]$ & Henning et al. (1997) \\
$\mathrm{SiO}[\mathrm{s}]$ & Philipp in Palik (1985) \\
$\mathrm{Mg}_{2} \mathrm{SiO}_{4}[\mathrm{~s}]$ & Jäger et al. (2003) \\
$\mathrm{MgSiO}_{3}[\mathrm{~s}]$ & Dorschner et al. (1995) \\
$\mathrm{MgO}_{\mathrm{s}}[\mathrm{s}$ & Hofmeister et al. (2003) \\
$\mathrm{Al}_{2} \mathrm{O}_{3}[\mathrm{~s}]$ & Begemann et al. (1997) \\
$\mathrm{Fe}[\mathrm{s}]$ & Ordal et al. (1985) \\
$\mathrm{FeO}[\mathrm{s}]$ & Henning et al. (1995) \\
$\mathrm{FeS}_{[}[\mathrm{s}]$ & Begemann et al. (1994) \\
$\mathrm{Fe}_{2} \mathrm{O}_{3}$ & http://www. astro.uni-jena.de/Laboratory/ \\
& OCDB/index.html \\
$\mathrm{CaTiO}_{3}[\mathrm{~s}]$ & Posch et al. (2003) \\
\hline
\end{tabular}

row Fig. 9), we remove a blackbody emission as a continuum $\left(B_{\lambda}\left(T_{\mathrm{bb}}\right)\right)$ from the spectrum $\left(F_{\lambda}\right)$ as

transmission $=F_{\lambda}\left(T\left[z_{0}(\lambda)\right]\right) / B_{\lambda}\left(T_{\mathrm{bb}}\right)$,

i.e. all transmission curves for one model atmosphere are divided by the same black body continuum: $\left(T_{\mathrm{eff}}, \log g ; T_{\mathrm{bb}}\right)=\{(1800 \mathrm{~K}$, $5.0 ; 1310 \mathrm{~K}),(1300 \mathrm{~K}, 5.0 ; 1205 \mathrm{~K}),(1300 \mathrm{~K}, 3.0 ; 910 \mathrm{~K})\}$. 

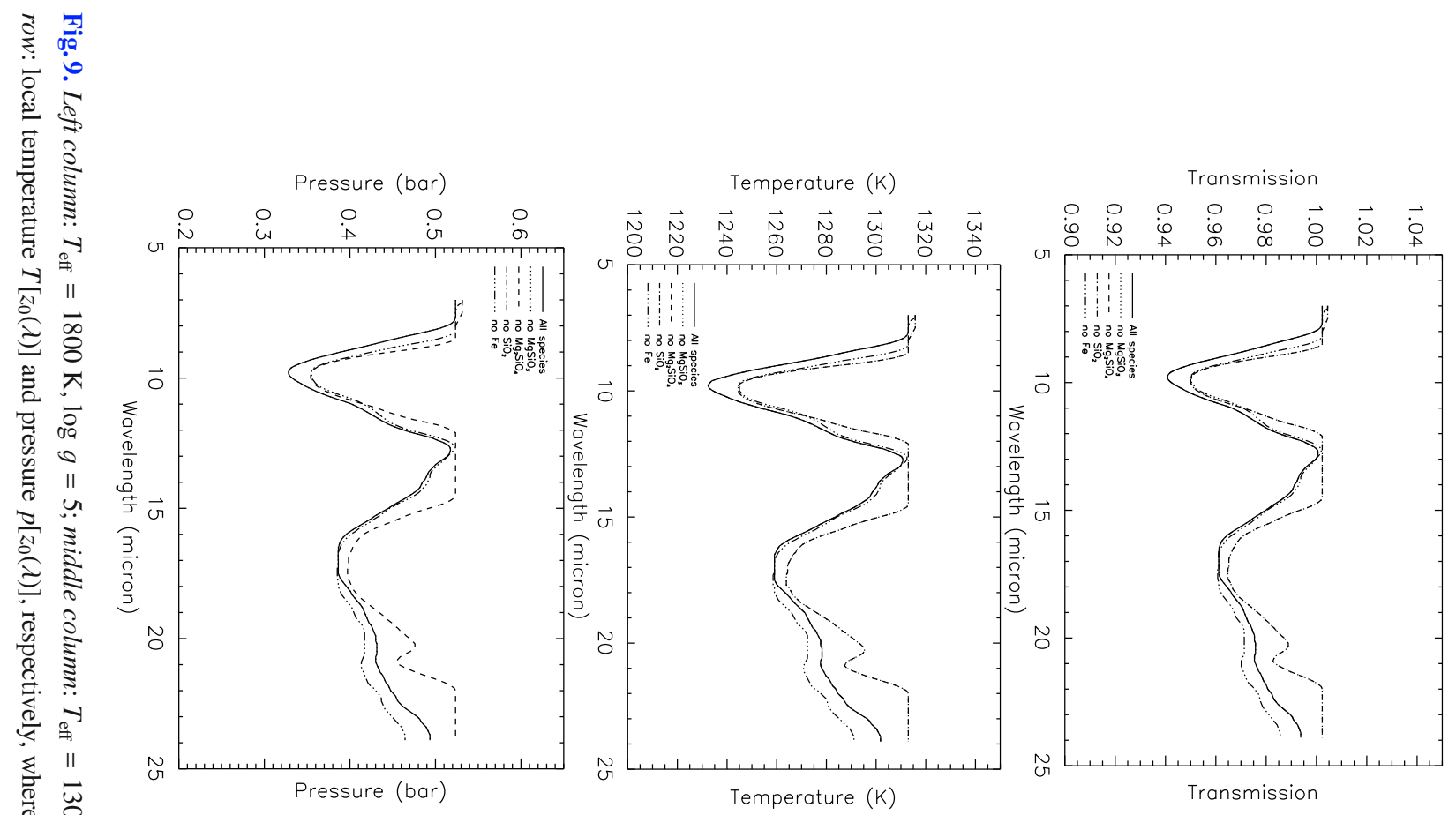

㟒.
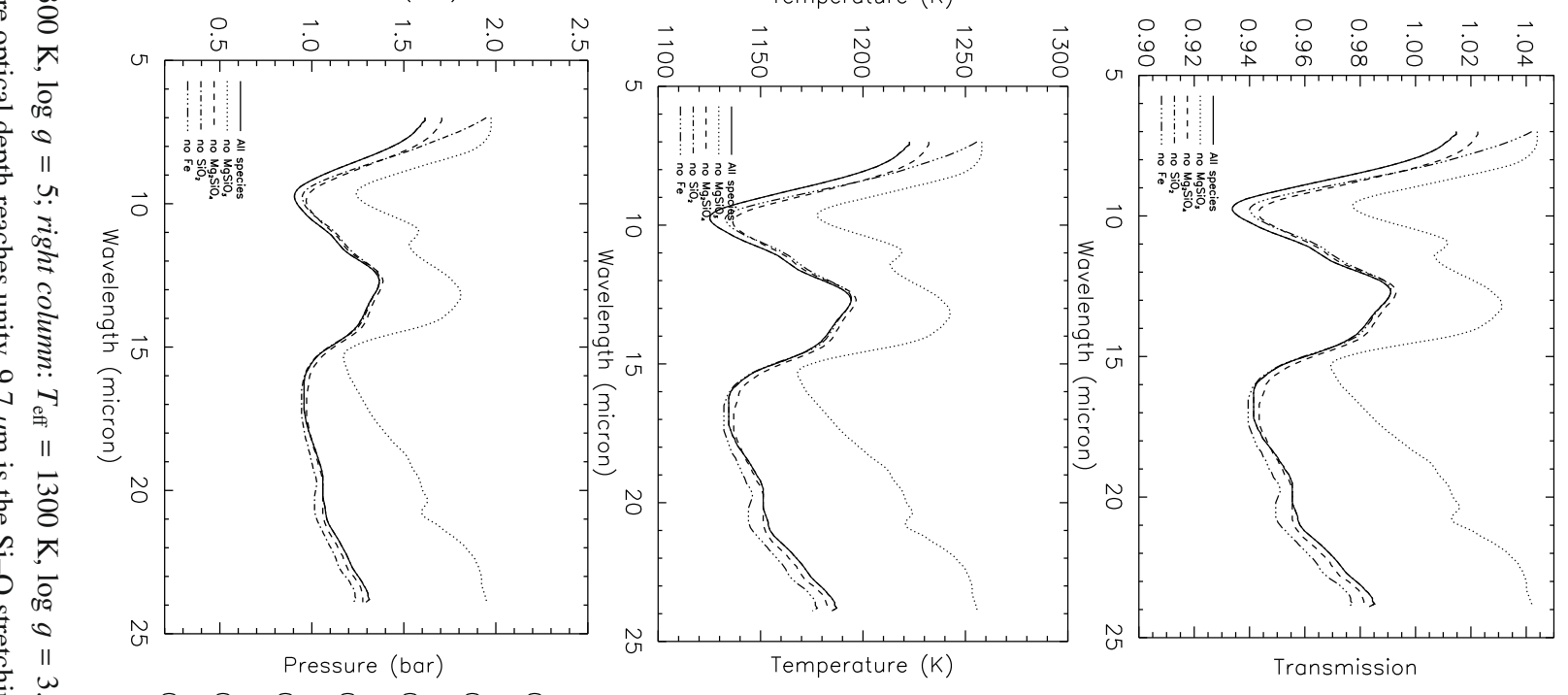

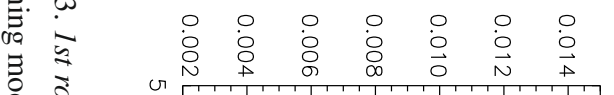
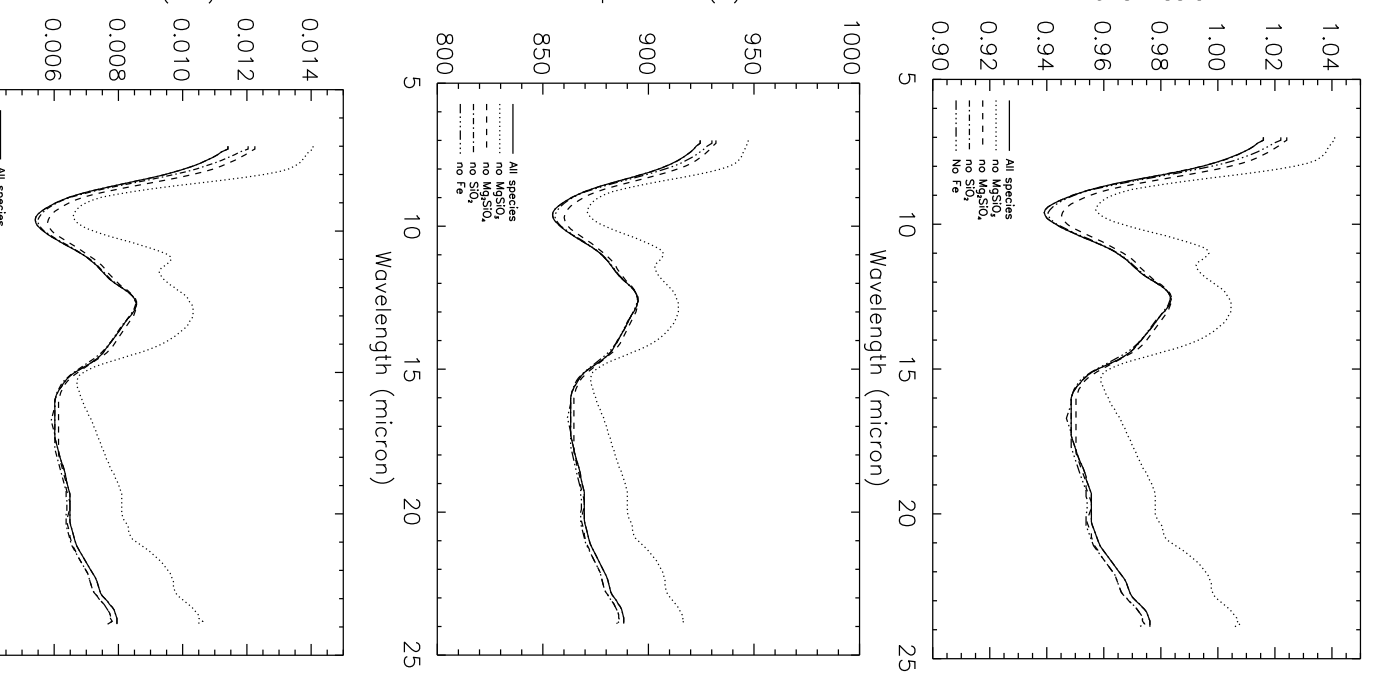


\subsection{Results}

The absorption features can be distinguished from the continuum in all cases. But they amount to a maximum of $6 \%$ only at $9.7 \mu \mathrm{m}$ in all three cases. The positions of the absorption features $(9.7 \mu \mathrm{m}$ and $17-18 \mu \mathrm{m})$ are typical of pure absorption by amorphous silicates, which implies that scattering by the larger grains in the size distribution does not contribute significantly to the total cross-sections. This result differs from the single grain size situation where scattering may modify the features, e.g. by shifting the peak absorptions.

The temperature and pressure at $z_{0}(\lambda)$, where $\tau_{\lambda}^{\text {dust }}=1$, are plotted below the transmission spectra. The weak absorption reflects the shallow temperature and pressure variations in the $\tau^{\text {dust }} \approx 1$ region. The contribution of quartz is negligible, as testified by the same output spectrum whether quartz opacity (dashdot line) is present or not. The two silicate species $\mathrm{MgSiO}_{3}$ and $\mathrm{Mg}_{2} \mathrm{SiO}_{4}$ contribute about equally to the output spectrum (dotted and dashed line).

Although grains exist even high in the atmosphere in this model, their number densities are too small to effect the opacity until the region of rapid grain growth is reached. The rapid grain growth implies a concomitant sudden rise in opacities. The phenomenon is particularly acute in the $\left(T_{\text {eff }}=1800 \mathrm{~K}\right.$, $\log g=5$ ) model. Therefore, the absorption features probe in particular the cloud deck. The inclusion of gas opacities in the radiative transfer model will complicate the $7-20 \mu \mathrm{m}$ spectra, definitively rendering the search for silicates features in brown dwarf atmospheres difficult.

\section{Summary and conclusions}

Based on a detailed micro-physical description of the formation of composite dust particles including nucleation, growth/evaporation and drift we have investigated the formation, chemical composition and spectral appearance of quasistatic cloud layers in quasi-static brown dwarf and gas-giant atmospheres. Our models show that

- There is one single cloud layer which stretches from about (1000-1300) K to (1600-1800) K, which shifts to slightly higher temperatures for higher $\log g$ values.

- The material composition of the cloud particles changes continuously through the cloud layer. The seed particles created high in the atmosphere are simultaneously covered by all kinds of solid materials, favouring the abundant condensates like $\mathrm{MgSiO}_{3}[\mathrm{~s}], \mathrm{Mg}_{2} \mathrm{SiO}_{4}[\mathrm{~s}], \mathrm{SiO}_{2}[\mathrm{~s}]$ and $\mathrm{Fe}[\mathrm{s}]$. As the particles sink deeper, the higher temperatures enforce partial evaporation which stepwise purifies the grains, leaving only the most stable condensates like $\mathrm{Fe}[\mathrm{s}]$ and $\mathrm{Al}_{2} \mathrm{O}_{3}[\mathrm{~s}]$ at the cloud base.

- The material composition described above is primarily a function of local temperature and robust against changes in $T_{\text {eff }}$ and $\log g$.

- The mean sizes of the cloud particles increase continuously through the cloud layer. The particles are found to be very small in the high atmospheric layers $(\langle a\rangle \approx 0.01 \mu \mathrm{m})$ with a relatively broad size distribution, but as large as several $100 \mu \mathrm{m}$ with a strongly peaked size distribution at cloud base, where they finally shrink due to evaporation and dissolve into the surrounding gas. The maximum particle sizes reached are larger for smaller log $g$.

- The gas is highly supersaturated in the upper atmosphere, where the nucleation takes place, but reaches a state close to saturation from the cloud deck downward for the abundant medium-temperature condensates. For high altitudes in general and for high-temperature condensates in particular, phase equilibrium is not valid, since the depletion timescale exceeds the mixing timescale.

- No cloud layer will form without the formation of seed particles, which is different from terrestrial planets where seed particles can be swept up from the crust.

- The consequence of the nucleation process is that the seed forming elements are more strongly depleted from the gas phase in the high atmosphere than those elements that need an alien surface to condense on, which leads to a highly Ti-depleted upper atmosphere in our model. This finding could be useful to identify first nucleation species in brown dwarfs and gas-giants.

- Our models predict a much smaller degree of gas phase depletion compared to phase-equilibrium models. The maximum metallicity depression is about 6 orders of magnitude in our model for $\mathrm{Mg}, \mathrm{Si}, \mathrm{Fe}$ and $\mathrm{Al}$. Therefore, age estimates based on phase-equilibrium models may have overestimated the brown dwarf's age considerably.

- As a result of the phase-non-equilibrium, the carriers of the metallic resonance lines, e.g. Na I, K I, remain more abundant at high altitudes which should make these lines deeper and broader in the red part of the spectrum. This has been shown in Johnas et al. (2008).

- The oxygen-depletion is not large enough to turn the premordially oxygen-rich substellar atmosphere into a carbonrich atmosphere with a carbon-to-oxygen ratio $>1$.

- The broad dust absorption features attributed to the Si-O stretching mode (centred at $9.7 \mu \mathrm{m}$ ) and the Si-O bending mode (around $18 \mu \mathrm{m}$ ) should be present in brown dwarf spectra, but their maximum absorption is weak $(<6 \%)$ and hence difficult to detect. The spectra primarily probe the cloud deck between about $850 \mathrm{~K}$ and $1300 \mathrm{~K}$, where $\mathrm{Mg}_{2} \mathrm{SiO}_{4}[\mathrm{~s}]$ and $\mathrm{MgSiO}_{3}[\mathrm{~s}]$ are the most important solid species. The positions of the dust absorption features $(9.7 \mu \mathrm{m}$ and $17-18 \mu \mathrm{m})$ are typical of pure absorption by amorphous silicates, which implies that scattering by the larger grains in the size distribution does not contribute significantly to the total cross-sections.

\section{Appendix A: Grain size distribution function}

In order to find the dust particle size distribution function $f(a)\left[\mathrm{cm}^{-4}\right]$ we switch to another set of dust moments $K_{j}$ where the integrals are performed in radius-space $a$ (Dominik et al. 1986; Gauger et al. 1990) rather than in volume space $V$ (Dominik et al. 1993). Substitution for $V=\left(4 \pi a^{3}\right) / 3$ yields

$K_{j}=\int_{a_{\ell}}^{\infty} f(a) a^{j} \mathrm{~d} a=\left(\frac{3}{4 \pi}\right)^{j / 3} \rho L_{j}$.

As argued in the main text, we are left with four known properties of the size distribution function, namely $K_{1}, K_{2}, K_{3}$ and $K_{4}$. We will introduce a suitable functional formula for $f(a)$ with a set of four free coefficients and will determine these coefficients from the known dust moments. This exercise is carried out for two functions in the following. 


\section{A.1. Double delta-peaked size distribution function}

One option is to consider the superposition of two Diracfunctions

$f(a)=N_{1} \delta\left(a-a_{1}\right)+N_{2} \delta\left(a-a_{2}\right)$,

where $\delta$ is the Dirac-function, $N_{1}, N_{2}\left[\mathrm{~cm}^{-3}\right]$ are two dust particle densities and $a_{1}, a_{2}[\mathrm{~cm}]$ are two particle radii.

Assuming $a_{1}>a_{\ell}$ and $a_{2}>a_{\ell}$, where $a_{\ell}$ is the lower integration size corresponding to $V_{\ell}$, the moments are given by $K_{j}=N_{1} a_{1}^{j}+N_{2} a_{2}^{j}$, from which we can determine the four free coefficients. $a_{1}$ is found to be the positive root of

$a_{1}^{2}\left(K_{2}^{2}-K_{1} K_{3}\right)+a_{1}\left(K_{1} K_{4}-K_{2} K_{3}\right)+\left(K_{3}^{2}-K_{2} K_{4}\right)=0$

and the other free coefficients are given by

$$
\begin{aligned}
& a_{2}=\frac{a_{1} K_{2}-K_{3}}{a_{1} K_{1}-K_{2}} \\
& N_{1}=\frac{\left(a_{1} K_{1}-K_{2}\right)^{3}}{\left(a_{1} K_{2}-K_{3}\right)\left(K_{3}-2 a_{1} K_{2}+a_{1}^{2} K_{1}\right)} \\
& N_{2}=\frac{K_{1} K_{3}-K_{2}^{2}}{a_{1}\left(K_{3}-2 a_{1} K_{2}+a_{1}^{2} K_{1}\right)} .
\end{aligned}
$$

\section{A.2. Potential exponential size distribution function}

Another, more continuous option is to consider the function

$f(a)=a^{B} \exp (A-C a)$,

which, for positive coefficients $A, B$ and $C$, is strictly positive with a maximum at $B / C$. Since there are only three coefficients in Eq. (A.7) we will determine them from $K_{1}, K_{2}$ and $K_{3}$.

To find a simple analytical solution, we extend the integration in Eq. (A.1) to the interval $[-\infty \ldots+\infty]$ which usually introduces only a small error, since $f(a)$ is quickly vanishing for small $a$ (see Fig. 8). The result is $K_{j}=\exp (A+\ln \Gamma(B+1+j)-$ $(B+1+j) \ln C)$, by which the free coefficients can be deduced:

$$
\begin{aligned}
& B=\frac{2 K_{1} K_{3}-3 K_{2}^{2}}{K_{2}^{2}-K_{1} K_{3}} \\
& C=(2+B) \frac{K_{1}}{K_{2}} \\
& A=\ln K_{1}+(2+B) \ln C-\ln \Gamma(2+B)
\end{aligned}
$$

where $\Gamma$ is the generalised factorial function with $\Gamma(n+1)=n$ ! for $n \in \mathbb{N}_{0}$ and $\Gamma(x+1)=x \Gamma(x)$ for $x \in \mathbb{R}^{+}$.

\section{References}

Ackerman, A. S., \& Marley, M. S. 2001, ApJ, 556, 872

Allard, F., Hauschildt, P. H., Alexander, D. R., et al. 2001, ApJ, 556, 357

Beckett, J. R., \& Stolper, E. 1994, Meteorotics, 29, 41

Begemann, B., Dorschner, J., Henning, T., Mutschke, H., \& Thamm, E. 1994, ApJ, 423, L71

Begemann, B., Dorschner, J., Henning, T., et al. 1997, ApJ, 476, 199

Bohren, C. F., \& Huffman, D. R. 1983, Absorption and scattering of light by small particles (New York: Wiley)
Cooper, C. S., Sudarsky, D., Milsom, J. A., et al. 2003, ApJ, 586, 1320

Cushing, M. C., Roellig, T. L., Marley, M. S., et al. 2006, ApJ, 648, 614

Cushing, M. C., Marley, M. S., Saumon, D., et al. 2007, ApJ, in press [arXiv: 0711.0801]

Dehn, M. 2007, Ph.D. Thesis, University Hamburg

Dominik, C., Gail, H.-P., \& Sedlmay, E. 1986, A\&A, 223, 227

Dominik, C., Sedlmay, E., \& Gail, H.-P. 1993, A\&A, 227, 578

Dorschner, J., Begemann, B., Henning, T., Jaeger, C., \& Mutschke, H. 1995, A\&A, 300, 503

Fegley, B. Jr., \& Lodders, K. 1994, Icarus, 110, 117

Ferguson, F. T., \& Nuth III, J. A. 2006, J. Chem. Engin. Data, submitted

Gail, H.-P., \& Sedlmayr, E. 1984, A\&A, 133, 163

Gauger, A., Sedlmayr, E., \& Gail H.-P. 1990, A\&A, 235, 345

Golimowski, D. A., Leggett, S. K., Marley, M. S., et al. 2004, AJ, 127, 3516

Hashimoto, A. 1990, Nature, 347, 53

Helling, Ch., \& Jørgensen, U. G. 1998, A\&A, 337, 477

Helling, Ch., Woitke, P. 2006, A\&A, 455, 325 (Paper V)

Helling, Ch., Woitke, P., Thi W.-F., \& Fridlund, M. 2006, A\&A, 451, L9

Helling, Ch., Dehn, M., Woitke, P., \& Hauschildt, P. 2008a, ApJ, 675, L105

Helling, Ch., Ackerman, A., Allard, F., et al. 2008b, Exoplanets: Detection, Formation and Dynamics, ed. Y.-S Sun, S. Ferraz-Mello, \& J.-L. Zhou, IAU Symp., 249, 173

Henning, T., \& Mutschke, H. 1997, A\&A, 327, 743

Henning, T., Begemann, B., Mutschke, H., \& Dorschner, J. 1995, A\&AS, 112, 143

Hofmeister, A. M., Keppel, E., \& Speck, A. K. 2003, MNRAS, 345, 16

Jäger, C., Dorschner, J., Mutschke, H., Posch, T., \& Henning, T. 2003, A\&A, 408, 193

Jeong, K. S., Chang, C., Sedlmayr, E., \& Sülzle, D. 2000, J. Phys. B, 33, 3417

Jeong, K. S., Winters, J. M., Le Bertre, T., \& Sedlmayr, E. 2003, A\&A, 407, 191

Johnas, C. M. S., Helling, Ch., Witte, S., et al. 2007, Proceeding to Extreme solar systems, ed. F. Rasio

Johnas, C. M. S., Helling, Ch., Dehn, M., Woitke, P., \& Hauschildt, P. H. 2008, MNRAS, in press [arXiv:0801.3544]

Kern, C. M., Witkowski, R. E., \& Cassidy, W. A. 1993, Metic, 28, 379

Korhonen, H., Napari, I, Timmreck, H., et al. 2003, JoGR, 108, D17, 4546

Lauretta, D. S., Kremser, D. T., \& Fegley, Jr. B. 1996, Icarus, 122, 288

Lecavelier Des Etangs, A., Pont, F., Vidal-Madjar, A., \& Sing, D. 2008, A\&A, 481,83

Ledieu, J., Hoeft, J. T., Reid, D. E., et al. 2005, Phys. Rev. B, 72, 035420

Levin, Z., Ganor, E., \& Gladstein, V. 1996, JAM 35(9), 1511

Lewis, J. S. 1997, Physics and Chemistry of the Solar System (Academic Press)

Ludwig, H. G., Allard, F., \& Hauschildt, P. H. 2002, A\&A, 395, 99

Ludwig, H. G., Allard, F., \& Hauschildt, P. H. 2006, A\&A, 459, 599

Ordal, M. A., Bell, R. J., Alexander, R. W., Long, L. L., \& Querry, M. R. 1985, Appl. Opt., 24, 4493

Palik, E. D. 1985, Handbook of optical constants of solids, 765

Patzer, A. B. C. 2004, ASP Conf. Ser., 309, 301

Pont, F., Knutson, H., Gilliland, R. L., Moutou, C., \& Charbonneau, D. 2008, MNRAS, 385, 109

Posch, T., Kerschbaum, F., Fabian, D., et al. 2003, ApJS, 149, 437

Ribarsky, M. W. 1985, in Handbook of Optical Constants, ed. E. D. Palik (Orlando: Academic Press), 795

Richardson, L. J., Deming, D., Horning, K., Seager, S., \& Harrington, J. 2007, Nature 445, 892

Rietmeijer, F. J. M., Nuth, J. A., \& Karner, J. M. 1999, ApJ, 527, 395

Rossow, W. B., Icar 76, 1

Seager, S., Turner, E. L., Schafer, J., \& Ford, E. B. 2005, Astrobiology, 5, 372

Sharp, C. M., \& Huebner, W. F. 1990, AJSS 72, 417

Swain, M. R., Akeson, R. L., Bouwman, J., Lawler, S., \& Beichman, C. A. 2008, ApJ, 674, 482

Toppani, A., Robert, F., Libourel, G., et al. 2005, Nature, 437(20), 1121

Tsuji, T. 2002, ApJ, 575, 264

Tsuji, T., Ohnaka, K., \& Aoki, W. 1996, A\&A, 305, 11

Warren, S. J., Mortlock, D. J., Leggett, S. K., et al. 2007, MNRAS 381(4), 1400

Woitke, P., \& Helling, Ch. 2003, A\&A, 399, 297 (Paper II)

Woitke, P., \& Helling, Ch. 2004, A\&A, 414, 335 (Paper III)

Woitke, P. 2006, A\&A, 460, L9

Young, P. A., Knierman, K. A., Rigby, J. R., \& Arnett, D. 2003, ApJ, 595, 1114

Zinke-Allmang, M. 1999, Thin Solid Films 346, 1 